\title{
Seasonal variation in infant mortality in India
}

\author{
Aashish Gupta*t
}

June 19, 2021

\begin{abstract}
Investigating seasonal variation in health helps understand interactions between population, environment, and disease. Using information on birth month-year, survival status within the first year of life, and age at death (if the infant died) of more than 330,000 children observed in the four rounds of India's Demographic and Health Surveys, I estimate period mortality rates between ages 0 and $1\left({ }_{1} \mathrm{~m}_{0}\right)$ by calendar month. Relative to the spring months, infant mortality is higher in the summer, monsoon, and winter months. If spring mortality conditions were prevalent throughout the year, ${ }_{1} \mathrm{~m}_{0}$ would have been reduced by 11.4 deaths per 1,000 in the early $1990 \mathrm{~s}$ and 3.7 deaths per 1,000 in the mid-2010s. Seasonal variation in infant mortality has declined, but remains higher among disadvantaged children. The results highlight the multiple environmental health threats that Indian infants face, and the short time of a year when these threats are less salient.
\end{abstract}

Keywords: Seasonality, Infant mortality, Child Health, Environment, India

*Email: aashishg@sas.upenn.edu Ph.D. Candidate, Demography \& Sociology, University of Pennsylvania, Pennsylvania, USA.

${ }^{\dagger}$ I am grateful to the editors and the anonymous reviewers, Amrut Bang, Jere Behrman, Pritha Chatterjee, Daniel Aldana Cohen, Diane Coffey, Vikrant Dadawala, Jean Drèze, Irma Elo, Michel Guillot, Payal Hathi, Sneha Mani, Devesh Kapur, Ridhi Kashyap, Hans-Peter Kohler, Bhargav Krishna, Megan Reed, Kanika Sharma, Alejandro Sánchez-Becerra, Dean Spears, David Sorge, Nikhil Srivastav, Nikkil Sudharsanan, Tariq Thachil, Yana Vierboom, Andrea Vehrlust, Atheendar Venkataramani, and Sangita Vyas for many helpful comments and suggestions. This research was supported by the IUSSP CRVS fellowship. 


\section{Seasonal variation in infant mortality in India}

\section{Introduction}

A large literature within the demographic and allied health sciences is concerned with documenting and understanding seasonal influences on health. Theses influences were recognized by many ancient texts which discussed them at length (Adams, 1849; Bhishagratna, 1963; Gruner, 1984; Veith, 2015). More contemporary studies on seasonality and health have contributed to the scientific understanding of health determinants, dynamics, and public policy. These studies have documented reductions in seasonal variation along the epidemiological transition in both historical and contemporary contexts (Delaunay et al., 2001; Rau, 2006b; Schlüter et al., 2020). They have also shed light on understand vulnerability to climactic factors (Rayco-Solon et al., 2004; Muhuri, 1996); identified the importance of household technologies, such as those related to temperature control (Kunst et al., 1991); motivated social security interventions in lean seasons (Behrman, 1988b; Drèze, 1990; Kumar et al., 2016); and quantified the likely impact of health interventions targeting seasonal diseases, such as malaria (Etard et al., 2004), influenza (Dorélien, 2019; Ho and Noymer, 2017), and diarrhea (Farrar et al., 2019).

Investigating seasonal variation in child health in low- and middle-income countries is an important priority within this literature for several reasons. First, children are particularly vulnerable to changes in the disease environment (Jutla et al., 2013; Geruso and Spears, 2018), and these vulnerabilities are likely to be higher in developing country contexts. Second, insults in childhood have adult health consequences (Elo and Preston, 1992; Doblhammer and Vaupel, 2001; Currie and Vogl, 2013). Thus, recognizing the timing of insults is critical to understanding interrelations of health across the life course. Third, reducing child mortality is a global health priority, as highlighted in the Sustainable De- 
velopment Goals (United Nations, 2015). Highlighting seasonal variation can motivate particular policy and behavioral interventions, such as for interventions that target seasonal diseases. Given increases in the provision of maternal and child health in low and middle income countries (UNICEF, 2019), healthcare systems and interventions could also prepare for seasonal healthcare needs.

Prior research has identified four broad categories of sources of seasonality in child health in low- and middle-income contexts. First, economic and agricultural activity in developing countries varies seasonally (Devereux et al., 2013; Chambers et al., 1981). Increased economic vulnerabilities and reduced access to nutrition is linked to morbidity and mortality (Rao et al., 2009). Second, environmental exposures, such as pollution, heat, humidity, and cold weather have direct impacts on health and they vary seasonally (Geruso and Spears, 2018; Guttikunda and Calori, 2013; Kumar et al., 2009). Third, disease dynamics, particularly for communicable diseases, are driven by population behaviors, environmental effects on hosts and pathogens, and their interactions (Fisman, 2007). In India, pneumonia and diarrhea, leading causes of infant mortality (Fadel et al., 2017), have been documented to vary seasonally (Farrar et al., 2019). A fourth source of seasonal variation in child health is seasonal variation in births (Dorélien, 2016; Rumisha et al., 2013; Pitt and Sigle, 1998). Seasonal variation in births has a compositional effect on seasonal estimates of infant mortality - some seasons have higher births, and thus a younger age-profile among infants, leading to more deaths (Knodel, 1983). Like seasonal diseases, seasonal variation in births may also increase the demand for healthcare. Given these multiple contributors, Fisman (2007) described seasonality in health and disease as "the final common expression of environmental and population patterns."

Studies on historical patterns of seasonality in contemporary high-income countries relied on population level mortality records, which in many cases, span several centuries (Rau, 2006b). In low- and middle-income contexts, the demographic literature has doc- 
umented a high-degree of seasonal variation based on sample registration (Farrar et al., 2019; Burkart et al., 2011) or surveillance site data (Muhuri, 1996; Kampe et al., 2015; Delaunay et al., 2001; Rumisha et al., 2013). Studies have also examined birth month or birth season effects on child height (Lokshin and Radyakin, 2012). However, studies of birth-month effects on child-height have been challenged due to methodological issues and data quality concerns (Larsen et al., 2019; Agarwal et al., 2017; Cummins, 2015). Although valuable, studies from surveillance sites study localized populations, and sample registration system often lack key information, such as the population exposed to the risk of death or household characteristics. Demographic and Health Surveys (DHS), which record calendar birth month, survival, and age at death in months for infants are a relatively under-utilized source in studies of seasonal variation in infant mortality. This omission is despite several advantages of examining seasonality in child mortality from these data. The DHS are more representative than surveillance sites, they measure a greater number of child health determinants than sample registration systems, and they have increasingly larger sample sizes, allowing for more precise estimation.

Using data from the DHS, this paper presents the first estimates of all-cause infant mortality by calendar-month for India, home to every sixth birth and every fifth infant death in the world according to United Nations (2015). I estimate period mortality rates between the ages 0 and $1\left({ }_{1} \mathrm{~m}_{0}\right)$ by calendar month. To account for seasonal variation in births, I compute age-standardized period-specific ${ }_{1} \mathrm{~m}_{0}$ by calendar month. The approach developed here examines seasonality in infant mortality over two decades, a period in which overall infant and child mortality have declined. Methodologically, the paper complements Pedersen and Liu (2012), finding that the Demographic and Health Surveys can be used to estimate mortality rates for shorter periods than the five-year estimates that DHS surveys typically report. Substantively, the paper contributes to the literature on environmental determinants of child health in developing countries. To my knowledge, this is the first paper to estimate infant mortality by calendar month using the DHS in 
India.

In the next section, I summarize the prior literature on seasonal variation in health and mortality. Section 3 presents data and methods, section 4 the main results, and section 5 presents several robustness checks. Section 6 concludes.

\section{Seasonality in health and mortality}

Seasonal variation in mortality is a result of complex interactions between behaviors, environmental exposures, effects on hosts and pathogens, and economic conditions (Chambers et al., 1981; Fisman, 2007; Rau, 2006b). The epidemiological transition and other social developments have also shaped seasonal variation in mortality. Before the Industrial Revolution, mortality in England used to be higher in the spring and winter months, and lower in the summer months (Wrigley et al., 1997). These seasonal patterns could be seen for all ages in other European countries as well and were relatively stable before the industrial revolution, with little attenuation over time. In London, as well as in French urban areas (Ariès, 1971), however, mortality used to be the highest in summer, likely due to infectious diseases. By the early 20th century, this summer peak had vanished due to improvements in hygiene and living standards (Rau, 2006b). During the rest of the 20th century, mortality differences between summer and winter declined as well, particularly after the decrease in respiratory track infections, possibly due to a reduction in air pollution (Kunst et al., 1991). Sakamoto-Momiyama (1978) finds a similar "deseasonalition" in mortality between 1900-1970 in the United States and Japan. Even then, Ho and Noymer (2017) find that in the US, pseudoseasonal life expectancy for winter months was higher by about a year than the summer months for the period 1960-2014.

In developing countries, data limitations do not permit such a long historical perspective on seasonal variations in mortality. However, data from Health and Demo- 
graphic Surveillance Sites (HDSS) in sub-Saharan Africa, stretching as far back as the 1950s, have been used by researchers to analyse patterns of seasonal variation in child mortality. Rayco-Solon et al. (2004) show that in Gambia, prior to 1975, deaths in the 'hungry' season (July-November) were 1.9 times as likely as deaths in the 'harvest' season (December-June). These odds reduced to 1.8 for the period 1975-1984, and 1.2 for the period 1984-1997 (Rayco-Solon et al., 2004). In Senegal, (Delaunay et al., 2001) found that although seasonality in mortality declined between 1960s and 1980s, it increased in the 1990s. These results suggest that seasonal patterns in mortality may not decline linearly.

To the extent that information on causes of death are available from surveillance sites, researchers have found that in Sub-Saharan Africa, along with diarrhea and pneumonia, malaria is a big component of both overall and seasonal variation in child mortality (Abdullah et al., 2007). In Senegal, mortality was highest in the rainy season of AugustSeptember (Delaunay et al., 2001). Etard et al. (2004) use verbal-autopsy information to find that the increase in seasonality was due to an increase in mortality due to malaria, diarrhea, fevers, and acute respiratory infections. Kampe et al. (2015) find a similar pattern of higher child-mortality in the rainy season months of June-October in an HDSS in Burkina Faso. These seasonal patterns were driven by malaria mortality among children, with no decline in mortality between 1998-2007. Abdullah et al. (2007) and Mutisya et al. (2010) confirm similar patterns from seven other surveillance sites in Sub-Saharan Africa, finding higher malaria mortality in the rainy seasons. Although it is well recognized that seasonal variation in Sub-Saharan Africa is larger, (Dorélien, 2016), studies have largely focused on the proportion of deaths in a year that occur in a month or season rather than on mortality rates.

In South Asia, studies based on both surveillance and sample registration data also find that child mortality varies seasonally. Becker (1981), Muhuri (1996), and Becker and Weng (1998) estimate seasonal mortality patterns for the Bangladesh HDSS site in Matlab 
for the periods 1972-1974, 1981-1982, and 1982-1990 respectively. All three papers found marked seasonality in child deaths in this area despite overall child mortality declines (Becker and Weng, 1998), as a result in part of many interventions to reduce child mortality (Chen et al., 1983). Major causes of death, such as diarrhea, respiratory diseases, injuries, and 'others', showed similar seasonal patterns. These patterns are also confirmed in sample registration data from Bangladesh for the period 2002-2007 by Burkart et al. (2011). Burkart et al. (2011) further find higher seasonal variation in child mortality for rural areas and families with lower socio-economic status.

Farrar et al. (2019) use sample registration data with causes of death coded on the basis of verbal autopsies to examine seasonal variation in death counts at the ages 1-59 months in India. These results are based on the Million Deaths Study (Gomes et al., 2017). They show that pneumonia deaths are highest in winter months in India, but also high in the summer and monsoon months. Diarrhea deaths, on the other hand, are highest in the summer and monsoon months, but also high in the winter months. Farrar et al. (2019) find that although child mortality declined in the period 2005-2013, seasonality in both pneumonia and diarrhea mortality still remains.

Higher mortality from these infectious diseases in the summer, monsoon, and winter months confirms known seasonal patterns of environmental exposures such as heat, humidity, cold temperatures, and air pollution. Heat and humidity is highest in the monsoon months in India, and exposure to fecal germs may also be high in the monsoon months (Pascual et al., 2002). Air pollution in India is caused by both perennial factors such as industrial activity, transportation, and solid fuel use for cooking, as well as seasonal activities such as stubble burning and solid fuel use for heating (Apte and Pant, 2019). In addition to seasonal sources of pollution, meteorological factors such as inversion which trap pollution close to the ground and are more likely to be observed in the winter months (Tiwari et al., 2013) cause higher exposure to air pollution in the these 
months.

In contrast to these studies finding evidence of seasonal variation in child mortality, studies using data from the DHS on child heights have had more mixed findings. For 40 developing countries including India, Agarwal et al. (2017) show that there is no correlation between height-for-age and month-of-birth. However, it is worth noting that this literature is concerned with month-of-birth effects, rather than seasonal variation in child health. Indeed, if a worse disease environment leads to higher mortality in particular seasons of a year, we may expect higher growth deficits if children were 'scarred' by the worse disease environment in particular months (Preston et al., 1998). However, to the extent that children who are more fragile die because of worse disease environment, the surviving cohort born in those months would likely be healthier. This selection mechanism linking early life circumstances and later health in (Preston et al., 1998) may in part account for the above findings.

Although there are exceptions, the social science literature on examining seasonal variation in mortality in India has preferred the approach of measuring mortality over calendar months, rather than seasons (Farrar et al., 2019; Larsen et al., 2019). This has advantages and disadvantages. Measuring mortality over longer periods will pool information, and seasonal estimates will have lower sampling variation than calendar month estimates. However, measuring mortality over calendar months allows for a finer understanding of seasonal variation. It also allows for greater flexibility, considering that seasons may not be uniform across India.

India is in the northern hemisphere. Although the intensity of the summer and winter months is influenced by wind patterns and varies over India's regions, these seasons are common across the country (Attri and Tyagi, 2010). In addition to the monsoon, Humidity is higher in India's coastal regions. The south-west monsoon varies within India, beginning in June in South India and proceeding to northern India by July, and withdrawing in 
September. Parts of South India receive rains from the receding monsoon, from September to November. Given the year to year variation in these seasonal patterns, as well as their variation across India, this paper also examines mortality by calendar month. To do this, the paper develops a methodological approach to estimate period ${ }_{1} \mathrm{~m}_{0}$ by calendar month. This allows a flexible approach. We study regional patterns as well as broader seasonal patterns that are common across India.

\section{Materials \& methods}

\subsection{Data}

The data used in this paper come from the National Family Health Surveys (NFHS), India's version of the DHS. I use the four existing waves of the NFHS, conducted in the years 1992-93, 1998-99, 2005-06, and 2015-2016. These multi-stage sample surveys, which are representative at the national and state level, obtain retrospective birth histories from women aged 15-49 years. In recalling their complete birth history, women surveyed are asked about:

- all the children they have ever had

- the month and year of birth of each child

- whether the child died

- age at death if the child died

For children who died within the first month of life, the DHS asks about the number of days the child was alive. For deaths in the first two years, the DHS asked about the number of months a child was alive. For deaths after age two years, the DHS asks about the number of years a child was alive.

To estimate mortality by calendar month (or any period), we need to estimate the 
number of deaths in a particular month (period), and the number of child-months (personperiods) lived in that month. Because the DHS asked the number of months a child was alive only for children who died before the age of 2 , mortality rates by calendar month can only be estimated for children under the age of 2 . However, because the bulk of child mortality in India is before the age of 1 (Hill et al., 2012), in this paper, I estimate period ${ }_{1} \mathrm{~m}_{0}$ for each calendar month. I do so by using the information on a child's month and year of birth of a child; their survival status; and if they died before the age of 1 , the number of months they were alive. The next sections describes this approach in detail.

\subsection{Approach: Creating a child-month dataset}

Using the DHS birth history module, I create estimates of infant mortality by calendar month. In the birth history module, each observation is a child. I convert this child dataset to a child-month dataset, where each observation is a child-month.

First, I assign every child 12 observations, one for each month in the first year of life they can be alive (0-11 months). This creates a child-month dataset. In this dataset, a child born in November 1989 will have 12 observations: one for November 1989, one for December 1989, one for January 1990, and so on, until October 1990. For each of these months, I also calculate the age (last month) the child attained, in months. So, the child described above will be aged 0 months in November 1989, 1 month in December 1989, 2 months in January 1990, 3 months in February 1990, and so on, until October 1990, when they will be aged 11 months.

Second, I calculate the month and year of death for children who died before the age of 1 . I do this by adding the age at death (in months) to their birth month and year. So, a child born in November 1989 who lived for 5 months would have died in April 1990. A child who died in the first month of life was assumed to have died in the birth month. 
Third, I create an indicator for whether a child was alive in a particular month or not. Thus, for this child who died at age 5 months in April 1990, the indicator for whether they died in a particular month will be zero for months 0 to 4 . In the linear regression approach I describe below, for month 5 , the indicator will be 1,000. This scaling of the binary indicator for whether a child died in that month to 0 or 1000 allows the interpretation of mortality estimates as deaths per 1,000 infants alive. I also create a dummy variable indicating 0 for alive and 1 for died in a month to use in a logistic and complementary-log-log (cloglog) regression framework.

Finally, I censor those-child months that are after the observation window, i.e. child months during or after the month-year of interview. Similarly, child-months after the death of a child are censored. These are child months a child did not live. After these steps, we have a child month dataset that has the following information for each childmonth:

- The month and year of observation

- The child's survival status (dead or alive) in that month and year of observation

- The child's age (in months) in that month and year of observation

- Other attributes of the child, such as sex, rural residence, or region

This approach assumes that all births and deaths are in the middle of the month. Deaths are assumed to be in the calendar-month an age is attained. It is compatible with other assumptions as well, which are listed in the supplementary appendix.

Estimates of early life mortality using the DHS are typically calculated for the period five years prior to the survey, to minimize recall errors. I follow this approach, and use in estimation all children born in the last five years. But I restrict estimates of infant mortality to the four years prior to the survey so that I can calculate both numerators (infants who died in the month) and denominators (children alive in the month) correctly. This makes sure that each calendar month in the analysis period has person-months contributed from 
children of all ages from zero to 11 months.

Another exclusion criterion is that only those months are included in the analysis in which children from all of India's states contribute person months. The DHS surveys in India are conducted in a phased manner. Interviewers visit states at different times within the survey period. Thus, for some initial months within the five-year period, only a few states contribute observations. Those months are dropped. This final criteria ensures that estimates of monthly infant mortality are not driven by differences in the states that contribute deaths and person-months to the calendar months.

\subsection{An example using a Lexis diagram}

This approach can be visualized in the Lexis diagram. Figure 1 helps understand the structure of the dataset and the strategy for estimating period ${ }_{1} \mathrm{~m}_{0}$ by calendar month. The Lexis diagram shows lifelines for 15 children. The children were born in fifteen different months, starting from January 1991 to March 1992. The Lexis diagram follows them for each month until they reach the age of 1 year, or until they die. Out of the 15 children followed here, 4 died before reaching the age of 1 year. Thus, child 1, 2, and 3 survived until age 1 year, but child 4 died at the age of 4 months, in August 1991. Child 5 lived for a full 12 months, child 6 died in the 1st month of their life, when their age was 0 month, and so on.

We are interested in estimating period-specific ${ }_{1} \mathrm{~m}_{0}$ for each calendar month. In this example, the first month for which we should estimate ${ }_{1} \mathrm{~m}_{0}$ is December 1991. This is because December 1991 is the first month for which all children who could contribute child-months actually do contribute person months. In this example, however, consider ${ }_{1} \mathrm{~m}_{0}$ for the month of January 1992. In this month, one child (child 10) died at the age of 3 months, while 10 children contributed person months. Thus, in this example, ${ }_{1} \mathrm{~m}_{0}$ for January 1992 would be 1 death per 10 children, or 100 deaths per 1,000. 
Finally, note that for January 1992, we have half a month contributed by child 1 to January 1992, and half a month contributed by child 13. In practice, the half-month contributed by child 1 is not counted, and the half month counted by child 13 is counted as a full month. In this, we have assumed that the child-months that children born in January 1991 would have contributed to January 1992 are equal to the extra person-months assigned to children born in January 1992 in of our approach (Goldman et al., 1984).

\subsection{Estimating unadjusted and age-standardized ${ }_{1} \mathrm{~m}_{0}$ by calendar month}

Age-specific mortality rates for a particular period and place take the form:

$$
{ }_{\mathrm{n}} m_{x}=\frac{{ }_{\mathrm{n}} d_{x}}{{ }_{\mathrm{n}} L_{x}}
$$

where $m_{\mathrm{n}} m_{\mathrm{x}}$ is the mortality rate between ages $x$ and $x+n$, calculated as the number of deaths $(d)$ in ages $x$ to $x+n$ in the time period under consideration divided by the personperiods $\left({ }_{n} L_{x}\right)$ lived in that time period. In our case, calculating mortality rates between the ages 0 and 1 for calendar month $t$, equation 1 can be modified to:

$$
{ }_{1} m_{0}^{t}=\frac{{ }_{1} \text { deaths }_{0}^{t}}{{ }_{1} \text { child months lived }},
$$

We approximate ${ }_{1}$ child months lived ${ }_{0}^{\mathrm{t}}$, the number of child-months lived between the ages 0 and 1 years in month $t$ by estimating the number of children alive in the middle of month $t$. This approach of using the middle of the month as an estimate of the childmonths lived in the year is based on the assumption that person-months grow linearly within the month (Preston et al., 2000). Thus, in the approach followed in this paper, 
period mortality rates for each calendar month are estimated as:

$$
{ }_{1} m_{0}^{t}=\frac{{ }_{1} \text { death } s_{0}^{t}}{{ }_{1} \text { children alive in the middle of the } \text { month }_{0}^{t}},
$$

Since I use individual level data to compute these period mortality rates, I weight individual level data by survey weights that the NFHS calculated. However, the first three NFHS surveys had much smaller sample sizes than the latest NFHS survey (NFHS-4). NFHS 1, 2 and 3 were representative at the level of the states in India, whereas NFHS-4 is representative for districts in India. To avoid biasing estimates towards the NFHS-4, I give each survey an equal weight, of 0.25 . Thus, for each observation in NFHS-1, I divided the survey weight by .1271 and multiplied them by 0.25 , because NFHS- 1 contributed $12.71 \%$ of the weighted observations in the overall sample. Similarly, weights of NFHS-2 observations were divided by .1571 and multiplied by 0.25 , weights of NFHS-3 observations were divided by .1313 and multiplied by 0.25 , and weights of observations were divided by 0.5909 and multiplied by 0.25 . The weighted mortality rate in the age $0-1$ in calendar month $t$ can be calculated as:

$$
{ }_{1} m_{0}^{t}=\frac{\sum_{i=1}^{I}(\text { died between age } 0 \text { to } 1 \text { in month } t)_{i} \times \text { weight } t_{i}}{\sum_{i=1}^{I}(\text { children between age } 0 \text { and } 1 \text { alive in middle of month } t)_{i} \times \text { weight }_{i}}
$$

Births also vary seasonally in India (Appendix Figure A1, Anand et al. 2000; Dyson 1991). To adjust for monthly variation in the age distribution of infants in each calendar month, I also compute age-standardized ${ }_{1} \mathrm{~m}_{0}$ by calendar month. Seasonal fluctuations in births create a high-proportion of younger children in some calendar-months relative to other calendar months. Mortality declines rapidly even in the first year of life (Guillot et al., 2012). Thus, a higher proportion of younger children is some calendar-months relative to others can lead to a higher mortality in those months. To compute age-standardized 
${ }_{1} \mathrm{~m}_{0}$ by calendar month, I use a reweighting standardization technique developed by DiNardo et al. (1996) and introduced to the demography literature by Geruso (2012). This reweighting technique is similar to direct age-standardization (Preston et al., 2000), except that the reweighting technique is applied to individual level data. I re-weight the distribution of ages in each calendar month to match the overall distribution of ages in that survey round. For this, I first estimate a reweighting function for each calendar month $t$ in survey round $r$. This reweighting function takes the form:

$$
\psi^{t, r}(a)=\frac{f(a \mid r)}{f(a \mid t)}
$$

where $f$ represents the probability distribution function and $a$ represents age (in months). This function standardizes the distribution of ages in each calendar month such that each calendar-month's age distribution matches the overall age-distribution in the survey round. Age-standardized ${ }_{1} \mathrm{~m}_{0}$ is calculated in this approach as:

$$
{ }_{1} m_{0}^{t, \text { asr }}=\frac{\sum_{i=1}^{I}(\text { died between age } 0 \text { to } 1 \text { in month } t)_{i} \times \text { weight }_{i} \times \psi^{t, r}\left(a_{i}\right)}{\sum_{i=1}^{I}(\text { children age } 0 \text { to } 1 \text { alive in middle of month } t)_{i} \times \text { weight }_{i} \times \psi^{t, r}\left(a_{i}\right)} .
$$

For both the estimated (equation 4) and age-standardized mortality rates (equation 6), I calculate standard errors accounting for the clustering of observations within primary sampling units.

The approach used here is compatible with other assumptions, and robust to alternative methodological approaches as well. The supplementary appendix discusses this further. 


\subsection{Regression based approaches to estimate relative differences in in- fant mortality by calendar month}

Because we have a child-month dataset with a binary outcome (survived or died), regression based approaches can be used to control for covariates and examine if seasonal variation differs by observed determinants of child health. I use three regression approaches: a linear probability model which examines if there are mean differences in mortality by calendar month relative to a reference month; a logistic regression model which estimates odds-ratios for the probability of dying in a particular month compared to a reference month; and a complementary-log-log model which computes hazard-ratios of the probability of mortality in a particular month compared to a reference month.

The linear probability regressions take the form:

$$
\begin{aligned}
d_{i j t} & =\sum_{m=1}^{11} \beta_{m} \mathbb{1}\left[\text { calendar mont }_{i j t}=m\right]+\text { rage }_{i j t}+\text { pperiod }_{i j t} \\
& + \text { oplace }_{i j}+\lambda \text { female }_{i j}+\text { ssurvey round }_{i j}+\varepsilon_{i j t},
\end{aligned}
$$

where $d$ is a binary indicator of whether a child $i$ in primary sampling unit $j$ in month $t$ died or not. The $\beta_{m} \mathrm{~s}$ are the primary coefficients of interest, indicating the difference in the probability of death in a particular month and a reference month. The reference calendar month used in this analysis is March. In alternative specifications, I control for age-in-month dummies, period (measured as linear year, linear month-year, or year dummies), dummies for place (such as rural residence and state or region), sex of the child, and the survey round. Note that the adjusting for dummies for age-in-months in regression based approaches is equivalent to the age-standardization approach described earlier (Case and Paxson, 2005).

Adjusting for the period allows us to account for the declining trend of infant mor- 
tality in the overall period of 1989-2014. Dummies for age in months allow us to account for the pattern of mortality by age within the first year. This controls for age distributional differences between months. It creates estimates of infant mortality by month that are analogous to age-standardized estimates in equation 6 . Because the interview month can influence the recall of birth or death months (Larsen et al., 2019), I also control for interview month dummies. I control for dummies for survey round to account for measurement error associated with the implementation of a particular wave of the NFHS.

To examine differences in seasonal variation by time characteristics such as ruralurban residence, mother's education, household wealth, sex of the child, and region, I also estimate stratified regressions. In these regressions, the sample is limited to those belonging to a particular characteristic. These regressions, for instance, compare mortality for girls in a particular calendar month against mortality for girls in a reference month. More formally, these regressions take the form

$$
\begin{aligned}
d_{i j t} \mid c & =\sum_{m=1}^{11} \beta_{m} \mathbb{1}\left[\text { calendar mont }_{i j t}=m\right]+\text { rage }_{i j t}+\text { pperiod }_{i j t} \\
& + \text { oplace }_{i j}+\lambda \text { female }_{i j}+\text { osurvey round }_{i j}+\varepsilon_{i j t},
\end{aligned}
$$

where $c$ is the characteristic to which the sample has been limited to.

The logistic regression is estimated with the same set of covariates, and takes the form:

$$
\begin{aligned}
\log \left(\frac{P_{i j t}}{1-P_{i j t}}\right) & =\sum_{m=1}^{11} \beta_{m} \mathbb{1}\left[\text { calendar mont }_{i j t}=m\right]+\text { rage }_{i j t}+\text { pperiod }_{i j t} \\
& +{\text { - } \text { place }_{i j}+\lambda \text { female }_{i j}+\text { psurvey round }_{i j}+\varepsilon_{i j t}}
\end{aligned}
$$

$P_{i j t}$ is the probability of death in month $t$ for child $i$ in primary sampling unit $j$. This 
logistic approach is exactly similar to the one followed by Rau (2006a) to understand seasonality in Sweden, except that the approach followed here uses dummies for calendar months instead of dummies for seasons. In a survival analysis sense, the model used above is equivalent to a discrete-time hazard model with a logistic link function (Singer and Willett, 2003). I report odds-ratios, which should be interpreted as the odds of death in month $t$ divided by the odds of death in March.

Finally, I estimate a hazard model with a complementary log-log link with the same explanatory variables. This cloglog model makes an assumption of proportional hazards and not proportional odds (Singer and Willett, 2003). The cloglog model has the advantage that it allows the interpretation of hazards as if they were in continuous time. The cloglog model takes the form:

$$
\begin{aligned}
& \log \left(-\log \left(1-P_{i j t}\right)\right)=\sum_{m=1}^{11} \beta_{m} \mathbb{1}\left[\text { calendar month }_{i j t}=m\right]+\text { rage }_{i j t}+\text { pperiod }_{i j t} \\
& + \text { oplace }_{i j}+\lambda \text { female }_{i j}+\text { osurvey round }_{i j}+\varepsilon_{i j t},
\end{aligned}
$$

For this model as well, I report exponentiated coefficients, which are hazard ratios (or relative risks) relative to the month of March. An advantage of the logistic and complementary log-log approaches over the linear regression approach is that the constant is not predicted at theoretically implausible values. An advantage of the linear regression approach is that model comparisons are straightforward (Mood, 2010).

In all regressions, I cluster standard errors at the level of the primary sampling unit. Although there are multiple observations per child in this dataset, all the observed childmonths for a child are still within a cluster. I also use calculated survey weights, as described in section 3.4 (equation 4). 


\section{Results}

\subsection{Summary statistics}

Table 1 shows summary statistics for the overall sample as well as for each of the survey rounds. Estimates for each of the NFHS rounds are weighted using the national women's weights. Overall estimates are weighted by the calculated weights, which divide the weights of the individual NFHS rounds in such a way that they contribute equally to the overall means. About 40,000 children were observed in the first three NFHS waves, and more than 200,000 were observed in NFHS-4.

Because of censoring and because some children died, we observe the average child for about 8.8 months. Overall, $6 \%$ of the children died in the four NFHS waves. The proportion of children who died declined from $7 \%$ to $4 \%$ between the 4 rounds, reflecting overall improvements in infant health (Drèze and Sen, 2013). It is worth pointing out that overall infant mortality levels observed in these rounds for close to the infant mortality rates from the Sample Registration System (ORGI, 2016), as well as infant mortality rates from the United Nations Inter-agency Group for Child Mortality Estimation (UN IGME, 2019). Auto-correlation for the outcome of death in a month was examined, and the patterns suggested seasonal variation. Girls were slightly less than half the sample. In all the four rounds, more than $70 \%$ of the children were in rural areas.

I divide the all India sample into 4 contiguous regions: North (comprising the states of Jammu and Kashmir, Himachal Pradesh, Haryana, Punjab, and Delhi); Central (comprising the states Uttarakhand, Uttar Pradesh, Rajasthan, Madhya Pradesh, Chattisgarh, Gujarat, Bihar, and Jharkhand); East (comprising the states Odisha, West Bengal, Sikkim, Manipur, Meghalaya, Arunachal Pradesh, Tripura, and Mizoram), and South (comprising the states Andhra Pradesh, Telangana, Maharashtra, Goa, Tamil Nadu, Kerala, and Karnataka). This classification, which closely follows classical patterns of Indian regional 
demography (Dyson and Moore, 1983), divides India into regions that are poorer and have a higher burden of disease (the central and the eastern states), and the richer and less resource-poor southern states. More than half of all children were observed in the central states, $27 \%$ in the southern states, $14 \%$ in the central states, and $6 \%$ in the northern states.

I also divide the states based on their broad climate patterns, following Farrar et al. (2019). NFHS-1, 2, and 3 do not make available the location of the primary sampling unit. I match locations of NFHS-4 primary sampling units to the 2017 Koppen-Geiger classification, based on Beck et al. (2018).

For measures of socioeconomic status, I consider mother's education and the assets a family owns. I divide mother's education into three categories: those with no education, between 1-8 years of education, and more than 8 years of education. Over the course of 25 years, education has increased. In 1992-93, 13\% of mothers had more than 8 years of education, and $65 \%$ had no education. By 2015-16, 39\% had more than 8 years of education, and $30 \%$ had no education. In assets, I consider the following assets: two-wheeler, car, and refrigerator. These three assets were consistently asked in the four survey rounds, are not directly linked to health, and have been consistent markers of wealth throughout this period. Because of the small proportion of households owning these assets in earlier NFHS rounds, I dichotomize the asset count into having at least one asset. About $14 \%$ of households owned any of these assets in 1992-93, 21\% in 1998-99, 32\% in 2005-06, and $74 \%$ in $2015-16$.

Table 2 also shows summary statistics, but for the overall data at the level of the observations, i.e. for the child months observed in the sample. Overall, we observed more than 2.9 million child months in the four NFHS rounds, and 12,479 deaths of children below the age of 1 . The table shows the proportion of these total child-months and mean deaths that were observed in each calendar-month. The distribution of child-months over 
the calendar months reflect pattern of fertility, survey timing, and censoring. Similarly, the observed mean deaths by calendar months reflects patterns of seasonal variation in mortality and the age distribution of children within each calendar month.

Figure 2 shows estimated ${ }_{1} \mathrm{~m}_{0}$ for each month-year included in the final analytical sample. These rates, which are not age-standardized, show a high degree of variation in ${ }_{1} m_{0}$, especially for the first three NFHS rounds, in the 1990s and 2000s. This variation has declined substantially only by NFHS 4, although there is still evidence of seasonal variation in infant mortality.

\subsection{Descriptive evidence of seasonal variation}

What are the overall seasonal patterns of infant mortality in India? Are differences between calendar months, observed in Figure 2 substantial? Figure 3 answers these questions. It shows estimated raw and age-standardized rates, calculated following the approaches described for equations 4 and 6, respectively.

The blue circles, which show estimated raw rates, show a high-degree of seasonal variation. Infant mortality is lowest in the spring months of February, March, and April (when summer begins) and highest in the monsoon month of August. Mortality is also high in the winter (December, January) and summer months (May, June). However, agestandardized rates, in red squares, show that at least some of the higher mortality in the monsoon months is because of a higher proportion of younger infants in those months. The age-standardized rates show highest mortality in the summer month of May and the winter month of January, which are higher than rates in the spring months of March. Although the confidence intervals overlap slightly, age standardized ${ }_{1} \mathrm{~m}_{0}$ is also higher in the peak monsoon month of August. 


\subsection{Evidence from regression based approaches}

In the mean ${ }_{1} \mathrm{~m}_{0}$ by calendar month reported in Figure 3, some of the variation in mortality rates is due to the variation in mortality rates by survey rounds and regions. To partial out this variation, I turn to regression based approaches. Table 3 shows results from linear (models 1-4), logistic (model 5) and complementary-log-log (model 6) regressions of the association between calendar months and infant mortality. All models adjust for calculated survey weights and report standard errors clustered at the level of the primary sampling unit.

For the linear probability model, model 1 does not control for any covariates, replicating the raw estimated infant mortality rates from Figure 2. Model 2 controls for demographic covariates: dummies for the age of the child (0-11) and sex of the child. Controlling for dummies of age (in months) is equivalent to age-standardization. Model 3 additionally controls for place: the state the child was born into and rural or urban residence. Model 4 controls for time variables: the interview month, the survey round, and the linear month-year. Observations are child-months. The mean IMR was 4.32 infant deaths per 1,000 per month (51.8 infant deaths per 1,000 per year).

The main differences in the linear probability model are in Models 1 and 2, which replicate the differences between raw and age-standardized ${ }_{1} \mathrm{~m}_{0}$ in Figure 2. Between models 2-4, adding additional controls for state, rural residence, survey round, interview month, or linear month year do not change the results. These models show that relative to March, infant mortality is higher in the winter months of January, October, November, December; the summer month of May, and the monsoon months of July and August. Marginal differences between March and these months range from 0.7 to 1 death per 1,000 per month. This difference in substantial: it translates to at least 8.4 additional infant deaths per 1,000 per year. This difference itself is greater than the total infant mortality in high-income countries in this period (UN inter-agency group for child mortality 
estimation, 2019).

Models 5 and 6 confirm these findings using a logistic and complementary-log-log link in these hazard models. Both models 5 and 6 control for all the covariates that model 4 controls for. Broadly, the relative odds and relative risks for mortality are between 1.1 to 1.2 times higher for the the summer, monsoon, and winter months than for the month of March. May and July have the highest mortality, followed by the winter months of November, December, and January.

Figure A5 examines if seasonal variation can be observed in both neonatal and postneonatal mortality. Because neonatal mortality is much higher than post-neonatal mortality, the figure reports results from logistic regression, which examines odds of neonatal (or post-neonatal) mortality in other months relative to march. The figure finds evidence of seasonal variation in both the neonatal and post-neonatal periods. Although infectious diseases play a greater role in the post-neonatal period, they are also important for neonates (Bhalotra et al.; Fadel et al., 2017). We find that seasonal variation in both the neonatal and post-neonatal period is similar to an extent. However, compared to march, neonatal mortality is higher in May, and post-neonatal mortality is higher in July and December.

\subsection{Decline and persistence in seasonal variation}

How have seasonal patterns of mortality changed over time? Over the twenty-five year period between 1990 and 2015, infant mortality has nearly halved. Does this decline in infant mortality correspond to a decline in seasonal variation? Figure 2 provides evidence from un-adjusted mortality rates for a decline in seasonal variation. Seasonality has declined particularly when comparing the latest NFHS round with earlier NFHS rounds.

Table 4 confirms these patterns from age standardized mortality rates for each calen- 
dar month by NFHS round. To measure the extent of variation between calendar months, it also shows the standard deviation, the coefficient of variation (standard deviation divided by the mean), and the standard deviation of the natural log of the mortality rates for each round. The coefficient of variation and the standard deviation of log mortality rates are similar measures, and measure relative variation in mortality. In contrast, the standard deviation measures absolute variation. The findings here show that relative and absolute deviation move together. The three measures of variation did not decline between the first three rounds. But variation did decline with the fourth NFHS round, confirming descriptive patterns seen in Figure 2. In terms of absolute rates, for the first three rounds, standard errors are large, because of smaller sample sizes in the first three rounds. The estimates still reveal that there is substantial variation in mortality in all four rounds, and that seasonal variation can still be seen in the latest NFHS round, for births in the recent period of 2011-2014.

The last panel in Table 4 considers how much infant mortality would be lower if the mortality conditions in March were prevalent throughout the year. For this, I estimate the ${ }_{1} \mathrm{~m}_{0}$ per year per 1,000 (estimates A) as annualized infant mortality rates observed in each of the survey rounds. Next, I calculate the ${ }_{1} \mathrm{~m}_{0}$ in a year if the mortality conditions in March were prevalent throughout the year by calculating annualized March ${ }_{1} \mathrm{~m}_{0}$ (estimates B). To do this, I scale observed ${ }_{1} \mathrm{~m}_{0}$ in March by the person-months observed for the whole of the year. Finally, I calculate the difference between estimates A and $\mathrm{B}$ to estimate the hypothetical reduction in infant mortality if differences in infant mortality if march mortality conditions were prevalent throughout. This exercise is an upper bound on the likely mortality reductions, because some of the lower mortality in the March months could be because of 'harvesting' of more diseased infants in the earlier winter months (Dorélien, 2019). The calculation still reveals a large role of seasonal variation: a reduction of about 11 deaths per 1,000 in the early 1990s if March rates prevailed throughout the year, and about 4 deaths less per 1,000 in the mid-2010s. 
Average mortality decline by calendar-month: A related questions is if mortality declined in some months faster than others. Figure 4 reports results from an interaction between calendar year (operationalized linearly) and calendar months (operationalized as dummies from January to December). The coefficient for year in Figure 4 is the average decline per year in the month of March. Thus, it shows that for the month of March, infant mortality declined at the rate of 0.1 deaths per 1,000 infants per month every year. The interaction coefficients, for calendar month by year, denote the additional decline in a particular month above the 0.1 deaths per 1,000 per month decline observed for March. These estimates show that mortality has declined for all months. Additionally, they suggest that mortality in the monsoon months and in the early winter months has declined slightly faster than the mortality in winter and summer months. Compared to March and Summer mortality declines, mortality in the monsoon months declined by an additional 0.05 deaths per 1,000 per year. However, these interaction estimates are not statistically different from zero, and the hypothesis that mortality declined similarly across calendar months cannot be ruled out.

\subsection{Differences by measures of socioeconomic disadvantage}

Are these seasonal differences in infant mortality patterned by measures of socioeconomic status? Figure 5 plots regression coefficients from separate regressions by residence, sex of the child, mother's education, and by household asset ownership. The reference month is March, and the sample is limited in these regressions to the observations belonging to a particular group.

Rural residence: Panel a) compares infant mortality in other calendar months in rural areas with infant mortality in March in rural areas. It also compares mortality in a particular calendar-month in urban areas to mortality in March in urban areas. Overall, rural areas have higher seasonality than urban areas. In no calendar month are differ- 
ences in urban areas statistically different from March. In rural areas, several months have higher mortality. Figure A2 examines seasonality in infant mortality by round and rural residence. This figure suggests that the seasonal variation in the overall urban patterns largely comes from the earlier NFHS rounds. By NFHS-4, there is little evidence of seasonal variation in urban areas. In rural areas, however mortality in the winter and summer months is markedly higher than mortality in March. Even at a low level of overall infant mortality, differences between months in NFHS-4 can be as high as one death per 1,000 per month in rural areas.

Sex of the child: Panel b) shows differences by the sex of the child. Males are more vulnerable to disease at all ages (Austad, 2011; Drevenstedt et al., 2008). However, in India, discrimination against female children leads to higher mortality among them (Murthi et al., 1995), particularly in the ages 1-4 years. In ages 0-1 years, male and female ${ }_{1} \mathrm{~m}_{0}$ are roughly equal (Sawyer, 2012; Rai et al., 2017). Prior research has suggested that this in itself is a reflection of gender bias, given that female mortality rates should be lower than male mortality rates (Kashyap and Behrman, 2020). Previous evidence has documented that in the presence of seasonal shocks, intra-household allocations favor boys compared to girls (Behrman, 1988a). To the extent that a worse disease environment affects boys more, we expect boys to have higher mortality rates in the calendar months where mortality is higher. Gender inequality within household in the presence of seasonal variation will predict equal mortality by sex, or higher mortality among girls. Figure 5 finds preliminary evidence that both factors are at play: in some months, such as July, both boys and girls have equally higher mortality. However, in other months, such as in November, boys have slightly higher mortality than girls. Because discrimination against female children and the causes of death are not directly observed here, we cannot say what the likely patterns by gender would be without discrimination. This is an crucial avenue for future research. 
Maternal education: Panel c) shows mortality rates by mother's education. I use three categories: no education, 1-8 years of education, and eight or more years of education, which corresponds to the number of years of education which are a constitutional right in India (Bhatty, 2014), and is a corresponding Sustainable Development Goal as well (United Nations General Assembly, 2015). A large literature, in the demographic and health sciences considers mother's education as a salient determinant of child health (Caldwell, 1994). The regression results suggest that although seasonal variation in mortality can be seen for all educational categories, seasonal variation is particularly salient among the children of least educated mothers. Additionally, the fact that there is seasonal variation even in children of mothers who have more than 8 years of education suggest that these patterns are not driven by measurement error. Existing evidence suggests that mothers with more education are more likely to recall their birth months correctly than mothers with less education (Manesh et al., 2008; Larsen et al., 2019), and even among these mothers, there is evidence of seasonal variation in mortality.

Household wealth: Panel d) finds that the bulk of the seasonal variation is in families that are poorer. Families that own either a motorcycle, car, or refrigerator have no seasonal variation in infant mortality. In the monsoon months, these families have lower mortality than in March, although differences are not statistically different from zero. Appendix Figure A3 shows that patterns by asset ownership are consistent across the earlier and latest NFHS rounds.

\subsection{Regional and climactic patterns}

Figure 6 shows coefficients and 95\% confidence intervals for infant mortality by calendar month from separate regressions for each region. The figure shows that seasonality in infant mortality is lowest in the southern states, and highest in the poorer central states of India. The southern states have lower mortality rates (Drèze and Sen, 2013) as well 
as a better early life disease environment (Million Death Study Collaborators and others, 2010), partly because they have better sanitation and lower solid fuel use (Office of the Registrar General and Census Commissioner of India, 2011). The southern states also have lesser variation across seasons, compared to north India, which may be driving these patterns. In the eastern states, mortality is highest in the winter month of November, while in the northern states, mortality is highest in the winter month of December and the summer month of June.

Figure 7 shows seasonal variation in mortality by Koppen-Geiger climate regimes, using data from the fourth round of the NFHS. In this round, we observe higher mortality in the tropical monsoon regions (areas of western ghats in India) in the month of August, when the monsoon is at its peak. Mortality is higher in April, May, and June in the Humid Subtropical region, which corresponds to the northern Indian plains. Although seasonal variation is seen in other regions as well, such as with higher mortality in June in the arid and desert regions, these patterns are less pronounced.

\section{Robustness}

Appendix figure A4 tests if the estimates in Table 3 Model 4 are robust to alternative specifications for time-trends (panel a) or age (panel b). In panel a), I consider 4 alternative ways to control for time trends: survey rounds, linear month years, linear year, and dummies for years. The regressions include all existing controls: for age dummies, sex of the child, state, and rural residence. Although the estimated coefficients and confidence intervals vary slightly, they are broadly similar for all regressions. Panel b) confirms patterns already observed in raw and age-standardized estimates (in figure 3). It also shows that linear age controls are similar to no controls for age, while controlling for age and a squared term for age is similar to dummies for age in months. 
Appendix figure A6 examines seasonal variation by access to household environmental technologies. The regression controls for household asset ownership. The figure suggests higher seasonal variation among households who do not use toilets or clean fuels for cooking. This is consistent with findings from the prior literature (Geruso and Spears, 2015; Bassani et al., 2010), which would expect greater exposure to infectious disease among households without access to environmental health technologies.

Finally, I consider the effects of age-misreporting and heaping. Panel a) of appendix figure A7 shows the number of deaths by month of death. Most deaths are in the first month, confirming patterns of high neonatal mortality in India (Sankar et al., 2016). The panel shows evidence of heaping around 6th months, when the number of deaths are higher than mortality in the 5th month. To test if this age-heaping biases mortality rates, panel $b$ ) in appendix figure $A 7$ compares ${ }_{1} \mathrm{~m}_{0}$ with ${ }_{1} \mathrm{~m}_{0}$ that exclude 6 month olds. The ${ }_{1} \mathrm{~m}_{0}$ estimates which exclude 6-month olds exhibit slightly higher seasonality than ${ }_{1} \mathrm{~m}_{0}$, suggesting that this age-misreporting biases estimates for calendar-months towards zero. Thus, if age-misreporting was lower, it is likely that estimates of seasonal variation would be even higher.

\section{Discussion}

This paper contributes evidence to the literature on environmental determinants of child health for the important case of India, home to every sixth birth and every fifth infant death in the world, in several ways. To my knowledge, this is the first paper to estimate period infant mortality rates by calendar month for India. The methodological approach outlined here, of estimating period mortality rates between ages 0 and 1 could for periods shorter than a year, using routinely collected survey data, can be used to study other time-varying determinants of child health or policy interventions. The approach esti- 
mates unadjusted and age-standardized mortality rates below the age of 1 for calendar months. Age-standardized mortality rates by calendar month in ages below 1 adjust for compositional differences created by seasonal variation in births (Knodel, 1983). The approach here is compatible with several assumptions about the exact occurrence of births and deaths. Although the development of alternative estimation strategies, such as those that assign death dates to replicate age patterns of mortality in the infant ages, would be valuable, the approach used here is robust to alternative estimation strategies as well, such as using randomly assigned birth-dates within the birth-month.

We cannot rule out that some of the variation in period-mortality estimates we observe could be because of lagged effects of disease environment prevailing in previous months. Another concern about the methodological approach followed here is that measurement error in calendar birth month and age at death may still bias estimates of mortality by calendar month. We are able to address these concerns to some extent. First, the paper documents seasonal variation in both the neonatal and post-neonatal period. This implies that overall seasonal variation is not just because of neonatal mortality in misreported birth months. Second, we show that unadjusted and age-standardized mortality rates are similar in January, a month which often gets a disproportionate number of misreported births (Larsen et al., 2019). Finally, although more deaths are reported at age six months than deaths at five or seven months, dropping six-month old children from the sample leads to similar results.

Substantively, the analysis presented here concludes that although seasonal variation in mortality has declined over the period 1989-2014. In particular, seasonal variation was considerably less in the recent period, 2011-14. Similar patterns have been observed in the context of the epidemiological transition in contemporary high and low-income countries as well (Rau, 2006a; Schlüter et al., 2020). In India, the period 2005-2014 saw declines in infant mortality, progress on other aspects of human development (Drèze et al., 2021), 
and increases in child health provision (Singh et al., 2019). Household ownership of basic assets, such as cleaner fuels, pucca homes, fans and coolers also increased to an extent. It is likely that these improvements contributed to declines in seasonal variation in infant mortality. An important priority for future research is to investigate the causes of declines in infant mortality and seasonal variation in India.

Despite these declines, the paper documents that seasonal variation remains a challenge, particularly in rural areas, and particularly among disadvantages sections of Indian society. Why this is the case, and what can be done about this is an urgent question for policy and research. The pattern of seasonal variation documented in this paper reveals a limited period within the year - the spring months of February and March - where threats to child health are less salient. This evidence has relevance for studies of the latelife-legacy of early life conditions as well as for studies assessing the association between environmental exposures and child mortality. It is consistent with the prior literature in India. This literature has found a large number of seasonally varying exposures - pollution, heat, humidity, and cold weather, and the monsoon (Spears, 2019; Fu et al., 2018; Brown et al., 2019). The results documented here are also consistent with existing studies using cause of death data, such as Farrar et al. (2019). Farrar et al. (2019) find evidence in support of variation in diarrhea and pneumonia related mortality in the post-neonatal period in the summer and the winter months.

On the whole, we find that given current technologies and incomes, infant mortality in March is lower by about 4 infant deaths per 1000 per year. This is a sizable compared to overall infant mortality in India and elsewhere. Further research, which examines the extent to which accounting for these seasonally varying exposures can explain seasonality in mortality would help further bolster the evidence on the relative importance of the mechanisms highlighted here. Seasonal variation in nutrition availability, agricultural work, and other economic determinants are also not directly examined here. Further 
studies examining seasonal variation in cause-specific mortality and patterns of social disadvantage, such as gender, can be helpful in understanding discrimination within the household. The NFHS surveys may not be powered to detect seasonal variation over finer geographic and time scales, even if seasons themselves vary within India in terms of timing and intensity. This is an important avenue for future research. These specific studies can contribute to overall evidence on the role of policy approaches to reduce seasonal variation.

\section{References}

Abdullah, S. et al. (2007). Patterns of age-specific mortality in children in endemic areas of sub-saharan africa. In Defining and Defeating the Intolerable Burden of Malaria III: Progress and Perspectives: Supplement to Volume 77 (6) of American Journal of Tropical Medicine and Hygiene. American Society of Tropical Medicine and Hygiene.

Adams, F. (1849). The genuine works of Hippocrates: Volume I. Sydenham society.

Agarwal, N., Aiyar, A., Bhattacharjee, A., Cummins, J., Gunadi, C., Singhania, D., Taylor, M., and Wigton-Jones, E. (2017). Month of birth and child height in 40 countries. Economics Letters, 157:10-13.

Anand, K., Kumar, G., Kant, S., Kapoor, S., et al. (2000). Seasonality of births and possible factors influencing it in a rural area of haryana, india. Indian pediatrics, 37(3):306-311.

Apte, J. S. and Pant, P. (2019). Toward cleaner air for a billion indians. Proceedings of the National Academy of Sciences, 116(22):10614-10616.

Ariès, P. (1971). Histoire des populations françaises. Ed. du Seuil.

Attri, S. and Tyagi, A. (2010). Climate profile of india. Environment Monitoring and Research Center, India Meteorology Department: New Delhi, India.

Austad, S. (2011). Chapter 23-sex differences in longevity and aging. Handbook of the Biology of Aging, pages 479-495.

Bassani, D. G., Jha, P., Dhingra, N., and Kumar, R. (2010). Child mortality from solid-fuel use in india: a nationally-representative case-control study. BMC public health, 10(1):1-9.

Beck, H. E., Zimmermann, N. E., McVicar, T. R., Vergopolan, N., Berg, A., and Wood, E. F. (2018). Present and future köppen-geiger climate classification maps at 1-km resolution. Scientific data, 5(1):1-12.

Becker, S. (1981). Seasonality of deaths in matlab, bangladesh. International journal of epidemiology, 10(3):271-280.

Becker, S. and Weng, S. (1998). Seasonal patterns of deaths in matlab, bangladesh. International journal of epidemiology, 27(5):814-823.

Behrman, J. R. (1988a). Intrahousehold allocation of nutrients in rural india: Are boys favored? do parents exhibit inequality aversion? Oxford Economic Papers, 40(1):32-54. 
Behrman, J. R. (1988b). Nutrition, health, birth order and seasonality: Intrahousehold allocation among children in rural india. Journal of Development Economics, 28(1):43-62.

Bhalotra, S. R., Diaz-Cayeros, A., Miller, G., Miranda, A., and Venkataramani, A. S. Urban water disinfection and mortality decline in lower-income countries. American Economic Journal: Economic Policy.

Bhatty, K. (2014). Review of elementary education policy in india: Has it upheld the constitutional objective of equality? Economic and Political Weekly, pages 100-107.

Bhishagratna, K. K. (1963). The sushruta samhita.[english translation based on the original sanskrit text.]. Varanasi, Chowkhamba, Sanskrit Series.

Brown, P., Maher, Y. I., Balakrishnan, K., Fu, S. H., Kumar, R., Chakma, J., Menon, G., Dikshit, R., Dhaliwal, R., Rodriguez, P. S., et al. (2019). Mortality from particulate matter 2. 5 in india: National prospective proportional mortality study.

Burkart, K., Khan, M. H., Krämer, A., Breitner, S., Schneider, A., and Endlicher, W. R. (2011). Seasonal variations of all-cause and cause-specific mortality by age, gender, and socioeconomic condition in urban and rural areas of bangladesh. International journal for equity in health, 10(1):32.

Caldwell, J. C. (1994). How is greater maternal education translated into lower child mortality? Health transition review, 4(2):224-229.

Case, A. and Paxson, C. (2005). Sex differences in morbidity and mortality. Demography, 42(2):189-214.

Chambers, R., Longhurst, R., Pacey, A., et al. (1981). Seasonal dimensions to rural poverty. Citeseer.

Chen, L. C., Rahman, M., D'Souza, S., Chakraborty, J., and Sardar, A. (1983). Mortality impact of an mch-fp program in matlab, bangladesh. Studies in family planning, pages 199-209.

Cummins, J. (2015). On the use and misuse of child height-for-age z-score in the demographic and health surveys. Technical report, working paper.

Currie, J. and Vogl, T. (2013). Early-life health and adult circumstance in developing countries. Annu. Rev. Econ., 5(1):1-36.

Delaunay, V., Etard, J.-F., Préziosi, M.-P., Marra, A., and Simondon, F. (2001). Decline of infant and child mortality rates in rural senegal over a 37-year period (1963-1999). International Journal of Epidemiology, 30(6):1286-1293.

Devereux, S., Sabates-Wheeler, R., and Longhurst, R. (2013). Seasonality, rural livelihoods and development. Routledge.

DiNardo, J., Fortin, N. M., and Lemieux, T. (1996). Labor market institutions and the distribution of wages, 1973-1992: A semiparametric approach. Econometrica, 64(5):10011044.

Doblhammer, G. and Vaupel, J. W. (2001). Lifespan depends on month of birth. Proceedings of the National Academy of Sciences, 98(5):2934-2939.

Dorélien, A. (2019). The effects of in utero exposure to influenza on birth and infant outcomes in the us. Population and development review, 45(3):489.

Dorélien, A. M. (2016). Birth seasonality in sub-saharan africa. Demographic Research, 34:761-796.

Drevenstedt, G. L., Crimmins, E. M., Vasunilashorn, S., and Finch, C. E. (2008). The rise 
and fall of excess male infant mortality. Proceedings of the National Academy of Sciences, 105(13):5016-5021.

Drèze, J. (1990). Famine prevention in india. The political economy of hunger, 2:13-122.

Drèze, J., Gupta, A., Parashar, S. A., and Sharma, K. (2021). Pauses and reversals of infant mortality decline in india in 2017 and 2018. Forthcoming, Economic and Political Weekly.

Drèze, J. and Sen, A. (2013). An uncertain glory: India and its contradictions. Princeton University Press.

Dyson, T. (1991). On the demography of south asian famines part ii. Population studies, 45(2):279-297.

Dyson, T. and Moore, M. (1983). On kinship structure, female autonomy, and demographic behavior in india. Population and development review, pages 35-60.

Elo, I. T. and Preston, S. H. (1992). Effects of early-life conditions on adult mortality: a review. Population index, pages 186-212.

Etard, J.-F., Le Hesran, J.-Y., Diallo, A., Diallo, J.-P., Ndiaye, J.-L., and Delaunay, V. (2004). Childhood mortality and probable causes of death using verbal autopsy in niakhar, senegal, 1989-2000. International Journal of Epidemiology, 33(6):1286-1292.

Fadel, S. A., Rasaily, R., Awasthi, S., Begum, R., Black, R. E., Gelband, H., Gerland, P., Kumar, R., Liu, L., Mathers, C., et al. (2017). Changes in cause-specific neonatal and 159-month child mortality in india from 2000 to 2015: a nationally representative survey. The Lancet, 390(10106):1972-1980.

Farrar, D. S., Awasthi, S., Fadel, S. A., Kumar, R., Sinha, A., Fu, S. H., Wahl, B., Morris, S. K., and Jha, P. (2019). Seasonal variation and etiologic inferences of childhood pneumonia and diarrhea mortality in india. eLife, 8.

Fisman, D. N. (2007). Seasonality of infectious diseases. Annu. Rev. Public Health, 28:127143.

Fu, S. H., Gasparrini, A., Rodriguez, P. S., and Jha, P. (2018). Mortality attributable to hot and cold ambient temperatures in india: a nationally representative case-crossover study. PLoS medicine, 15(7):e1002619.

Geruso, M. (2012). Black-white disparities in life expectancy: how much can the standard ses variables explain? Demography, 49(2):553-574.

Geruso, M. and Spears, D. (2015). Neighborhood sanitation and infant mortality. Technical report, National Bureau of Economic Research.

Geruso, M. and Spears, D. (2018). Heat, humidity, and infant mortality in the developing world. Technical report, National Bureau of Economic Research.

Goldman, N., Pebley, A. R., and Lord, G. (1984). Calculation of life tables from survey data: A technical note. Demography, 21(4):647-653.

Gomes, M., Begum, R., Sati, P., Dikshit, R., Gupta, P. C., Kumar, R., Sheth, J., Habib, A., and Jha, P. (2017). Nationwide mortality studies to quantify causes of death: relevant lessons from india's million death study. Health Affairs, 36(11):1887-1895.

Gruner, O. C. (1984). A treatise on the canon of medicine of avicenna. Incorporating a Translation of the First Book.

Guillot, M., Gerland, P., Pelletier, F., and Saabneh, A. (2012). Child mortality estimation: a global overview of infant and child mortality age patterns in light of new empirical data. PLoS medicine, 9(8):e1001299. 
Guttikunda, S. K. and Calori, G. (2013). A gis based emissions inventory at $1 \mathrm{~km} \times 1 \mathrm{~km}$ spatial resolution for air pollution analysis in delhi, india. Atmospheric Environment, 67:101-111.

Hill, K. (1995). Age patterns of child mortality in the developing world. Population bulletin of the United Nations, (39):112-132.

Hill, K., You, D., Inoue, M., and Oestergaard, M. Z. (2012). Child mortality estimation: accelerated progress in reducing global child mortality, 1990-2010. PLoS medicine, 9(8):e1001303.

Ho, T. and Noymer, A. (2017). Summertime, and the livin'is easy: Winter and summer pseudoseasonal life expectancy in the united states. Demographic Research, 37:14451476.

Jutla, A., Whitcombe, E., Hasan, N., Haley, B., Akanda, A., Huq, A., Alam, M., Sack, R. B., and Colwell, R. (2013). Environmental factors influencing epidemic cholera. The American journal of tropical medicine and hygiene, 89(3):597-607.

Kampe, E. O. i., Müller, O., Sie, A., and Becher, H. (2015). Seasonal and temporal trends in all-cause and malaria mortality in rural burkina faso, 1998-2007. Malaria journal, 14(1):300.

Kashyap, R. and Behrman, J. (2020). Gender discrimination and excess female under-5 mortality in india: A new perspective using mixed-sex twins. Demography, 57(6):21432167.

Knodel, J. (1983). Seasonal variation in infant mortality: an approach with applications. In Annales de démographie historique, pages 208-230. JSTOR.

Kumar, S., Molitor, R., and Vollmer, S. (2016). Drought and early child health in rural india. Population and Development Review, pages 53-68.

Kumar, V., Shearer, J., Kumar, A., and Darmstadt, G. (2009). Neonatal hypothermia in low resource settings: a review. Journal of Perinatology, 29(6):401.

Kunst, A., Looman, C., and Mackenbach, J. (1991). The decline in winter excess mortality in the netherlands. International Journal of Epidemiology, 20(4):971-977.

Larsen, A. F., Headey, D., and Masters, W. A. (2019). Misreporting month of birth: Diagnosis and implications for research on nutrition and early childhood in developing countries. Demography, 56(2):707-728.

Lokshin, M. and Radyakin, S. (2012). Month of birth and children's health in india. Journal of Human Resources, 47(1):174-203.

Manesh, A. O., Sheldon, T. A., Pickett, K. E., and Carr-Hill, R. (2008). Accuracy of child morbidity data in demographic and health surveys. International journal of epidemiology, 37(1):194-200.

Million Death Study Collaborators and others (2010). Causes of neonatal and child mortality in india: a nationally representative mortality survey. The Lancet, 376(9755):18531860.

Mood, C. (2010). Logistic regression: Why we cannot do what we think we can do, and what we can do about it. European sociological review, 26(1):67-82.

Muhuri, P. K. (1996). Estimating seasonality effects on child mortality in matlab, bangladesh. Demography, 33(1):98-110.

Murthi, M., Guio, A.-C., and Dreze, J. (1995). Mortality, fertility, and gender bias in india: 
A district-level analysis. Population and development review, pages 745-782.

Mutisya, M., Orindi, B., Emina, J., Zulu, E., and Ye, Y. (2010). Is mortality among under-five children in nairobi slums seasonal? Tropical medicine $\mathcal{E}$ international health, 15(1):132-139.

Office of the Registrar General and Census Commissioner of India (2011). Census of india 2011: Household listing operations. Office of the Registrar General Census Commissioner, India. Indian Census Bureau.

ORGI (2016). Compendium of India's Fertility and Mortality Indicators 1971-2013 based on the Sample Registration System (SRS). Report, Office of the Registrar Genegral and Census Commissioner of India, New Delhi, Government of India.

Pascual, M., Bouma, M. J., and Dobson, A. P. (2002). Cholera and climate: revisiting the quantitative evidence. Microbes and Infection, 4(2):237-245.

Pedersen, J. and Liu, J. (2012). Child mortality estimation: appropriate time periods for child mortality estimates from full birth histories. PLoS Medicine, 9(8):e1001289.

Pitt, M. M. and Sigle, W. (1998). Seasonality, weather shocks and the timing of births and child mortality in Senegal. Brown University, Population Studies and Training Center Providence, RI.

Preston, S., Heuveline, P., and Guillot, M. (2000). Demography: Measure and modeling population processes.

Preston, S. H., Hill, M. E., and Drevenstedt, G. L. (1998). Childhood conditions that predict survival to advanced ages among african-americans. Social science $\mathcal{E}$ medicine, 47(9):1231-1246.

Rai, S. K., Kant, S., Srivastava, R., Gupta, P., Misra, P., Pandav, C. S., and Singh, A. K. (2017). Causes of and contributors to infant mortality in a rural community of north india: evidence from verbal and social autopsy. BMJ open, 7(8):e012856.

Rao, S., Kanade, A. N., Yajnik, C. S., and Fall, C. H. (2009). Seasonality in maternal intake and activity influence offspring's birth size among rural indian mothers-pune maternal nutrition study. International Journal of Epidemiology, 38(4):1094-1103.

Rau, R. (2006a). The impact of social factors on excess winter mortality in denmark. Seasonality in Human Mortality: A Demographic Approach, pages 125-168.

Rau, R. (2006b). Seasonality in human mortality: A demographic approach. Springer Science \& Business Media.

Rayco-Solon, P., Moore, S. E., Fulford, A. J., and Prentice, A. M. (2004). Fifty-year mortality trends in three rural african villages. Tropical medicine $\mathcal{E}$ international health, 9(11):11511160.

Rumisha, S., Smith, T., Abdulla, S., Masanja, H., and Vounatsou, P. (2013). Assessing seasonal variations and age patterns in mortality during the first year of life in tanzania. Acta tropica, 126(1):28-36.

Sakamoto-Momiyama, M. (1978). Changes in the seasonality of human mortality: a medico-geographical study. Social Science and Medicine, 12(1D):29-42.

Sankar, M., Neogi, S., Sharma, J., Chauhan, M., Srivastava, R., Prabhakar, P., Khera, A., Kumar, R., Zodpey, S., and Paul, V. (2016). State of newborn health in india. Journal of Perinatology, 36(s3):S3.

Sawyer, C. C. (2012). Child mortality estimation: estimating sex differences in childhood 
mortality since the 1970s. PLoS Medicine, 9(8):e1001287.

Schlüter, B.-S., Masquelier, B., Metcalf, C. J. E., and Rasoanomenjanahary, A. (2020). Longterm trends in seasonality of mortality in urban madagascar: the role of the epidemiological transition. Global health action, 13(1):1717411.

Singer, J. D. and Willett, J. B. (2003). Applied longitudinal data analysis: Modeling change and event occurrence. Oxford university press.

Singh, A., Kumar, K., and Singh, A. (2019). What explains the decline in neonatal mortality in india in the last three decades? evidence from three rounds of nfhs surveys. Studies in family planning, 50(4):337-355.

Spears, D. (2019). AIR: pollution, climate change and indias choice between policy and pretence. Harper Collins India.

Tiwari, S., Srivastava, A. K., Bisht, D. S., Parmita, P., Srivastava, M. K., and Attri, S. (2013). Diurnal and seasonal variations of black carbon and pm2. 5 over new delhi, india: Influence of meteorology. Atmospheric Research, 125:50-62.

UN IGME (2019). Estimates developed by the un inter-agency-group for child mortality estimation.

UN inter-agency group for child mortality estimation (2019). Levels and trends in child mortality 2019, estimates developed by the united nations inter-agency group for child mortality estimation. United Nations Children's Fund.

UNICEF (2019). The state of the world's children 2019. Un report, UNICEF.

United Nations (2015). World population prospects: The 2015 revision. United Nations Econ Soc Aff, 33(2):1-66.

United Nations General Assembly (2015). Sustainable development goals. SDGs Transform Our World, 2030.

Veith, I. (2015). The yellow emperor's classic of internal medicine. Univ of California Press.

Wrigley, E. A., Davies, R. S., Schofield, R., and Oeppen, J. (1997). English population history from family reconstitution 1580-1837. Number 32. Cambridge University Press. 
Figure 1: Lexis-Diagram containing life-lines and deaths to illustrate how ${ }_{1} \mathrm{~m}_{0}$ by month is calculated for a particular month (January 1992)

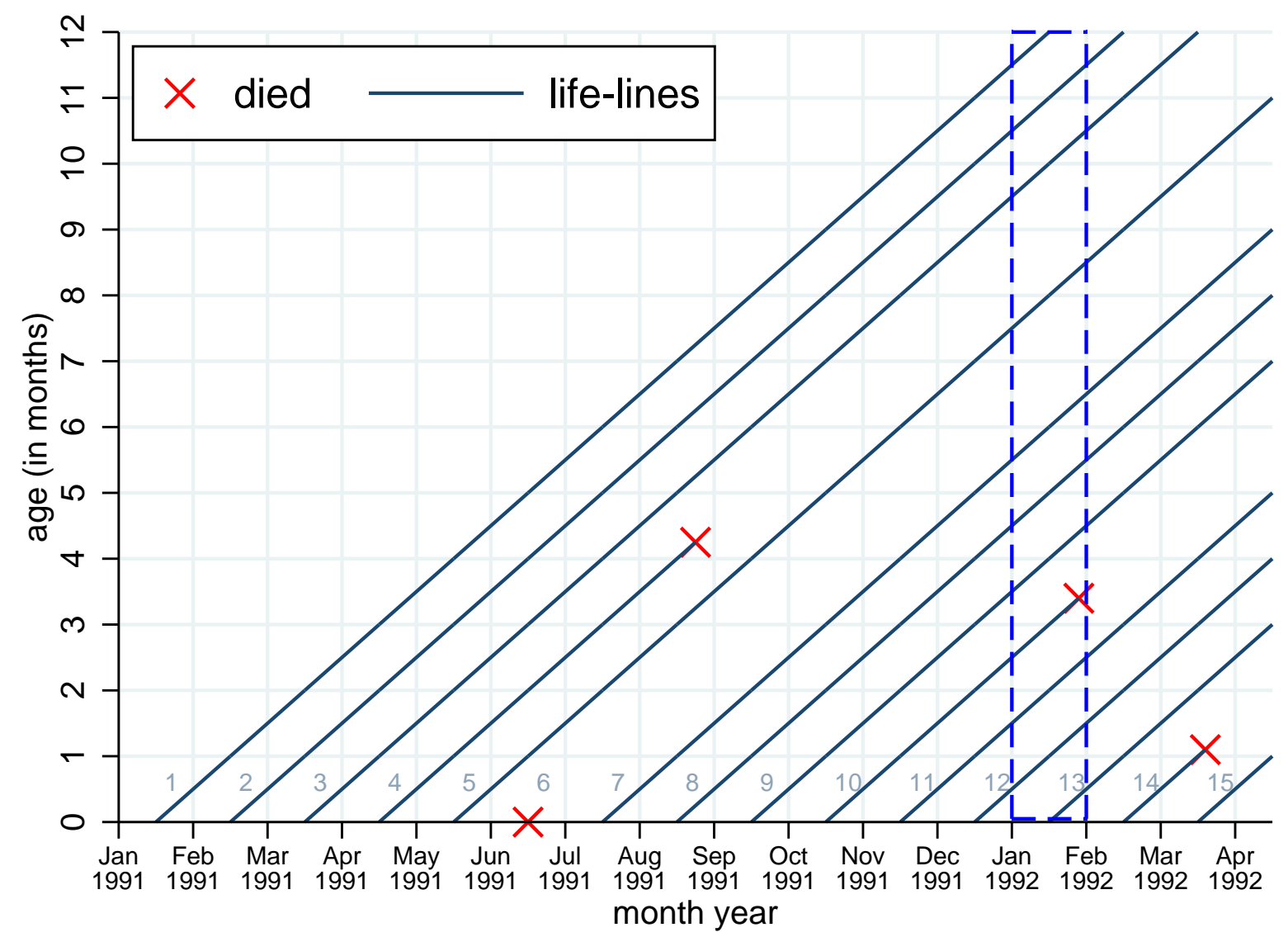

I estimate period-specific infant mortality rates, where each period is a calendar month-year. For example, to estimate the infant mortality rate for January 1992, the numerator consists of all deaths that occur to infants less than 1 year old in January 1992. The denominator consists of children below age 1 who are alive on January 15, 1992. The Lexis diagram in Figure 1 shows life-lines and deaths for 15 children, from birth to age 1 year. Of these 15, 4 died before reaching the age of 1 year. For the period January 1992, marked by blue dashed lines, there was 1 death (child id 10), and 10 children were exposed to the risk of death. The mortality rate for children under the age of 1 year for January 1992 in this hypothetical example would thus be 100 deaths per 1,000. 
Figure 2: Estimated of infant mortality $\left({ }_{1} \mathrm{~m}_{0}\right)$ by calendar month-year
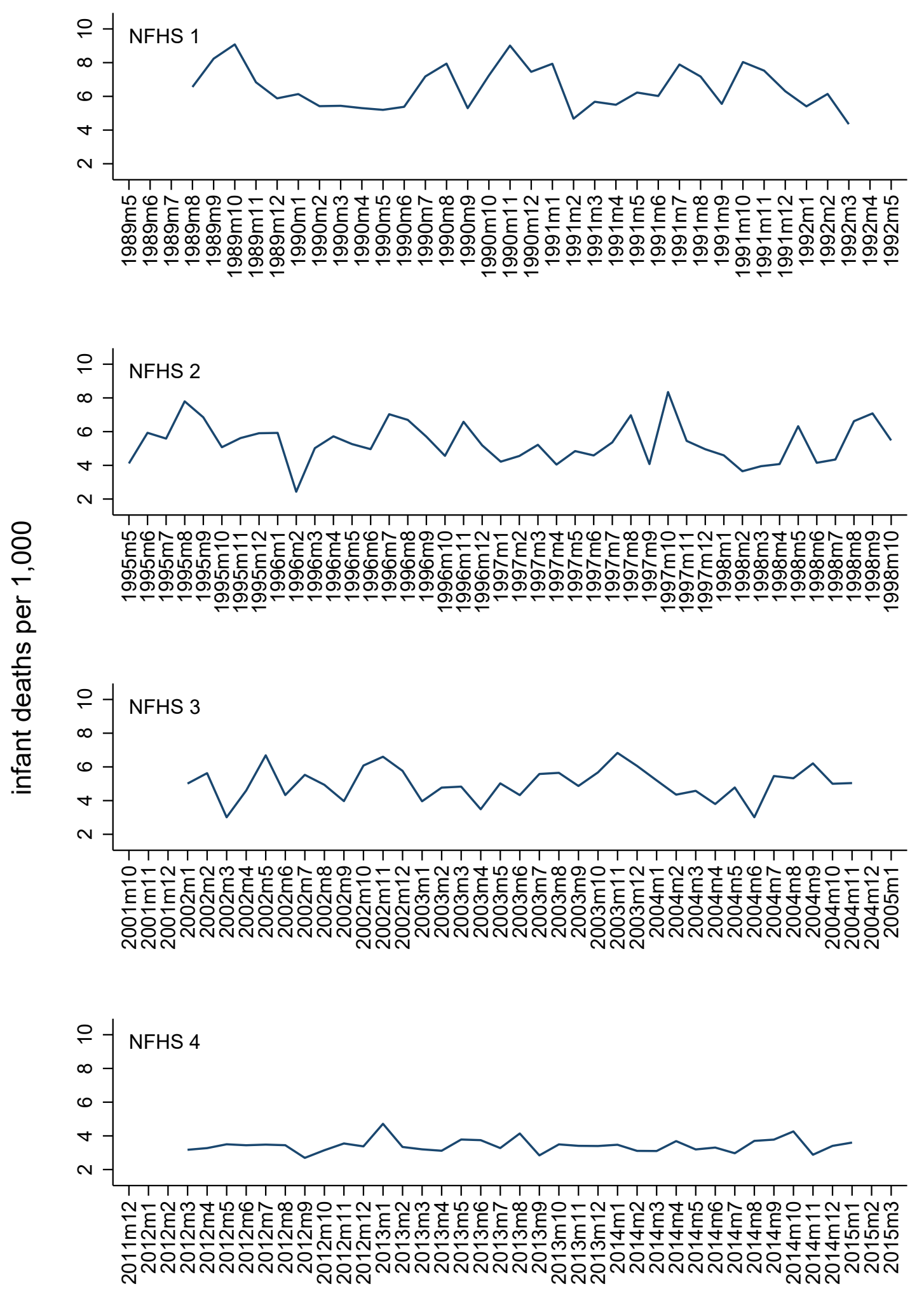

month-year

Note: Estimates account for survey weights. 
Figure 3: Estimated raw and age-standardized ${ }_{1} \mathrm{~m}_{0}$ with $95 \%$ confidence intervals by calendar month

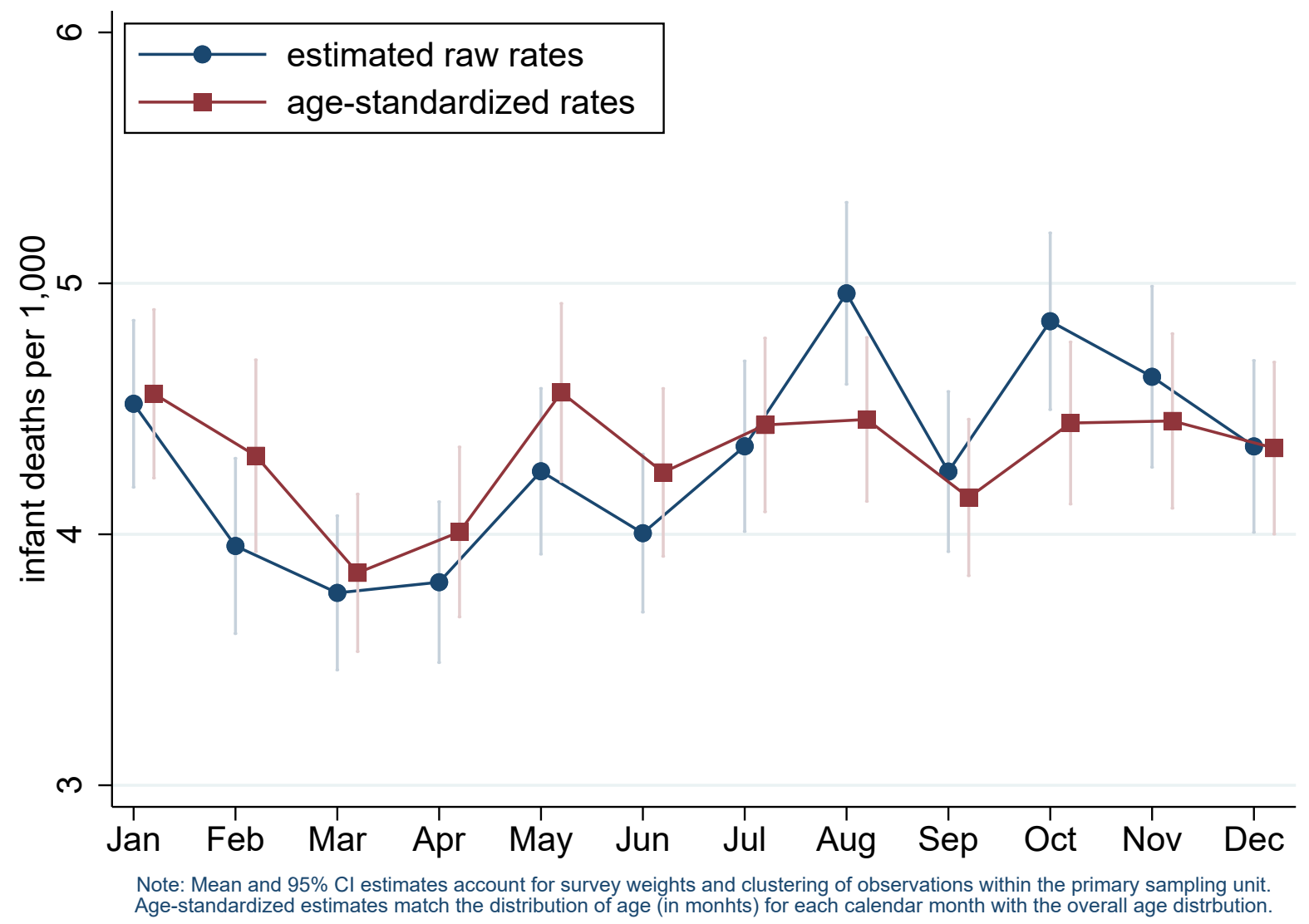


Figure 4: Plotted coefficients from linear probability regression interacting linear year and calendar month to examine if decline in infant mortality is higher for some calendar months

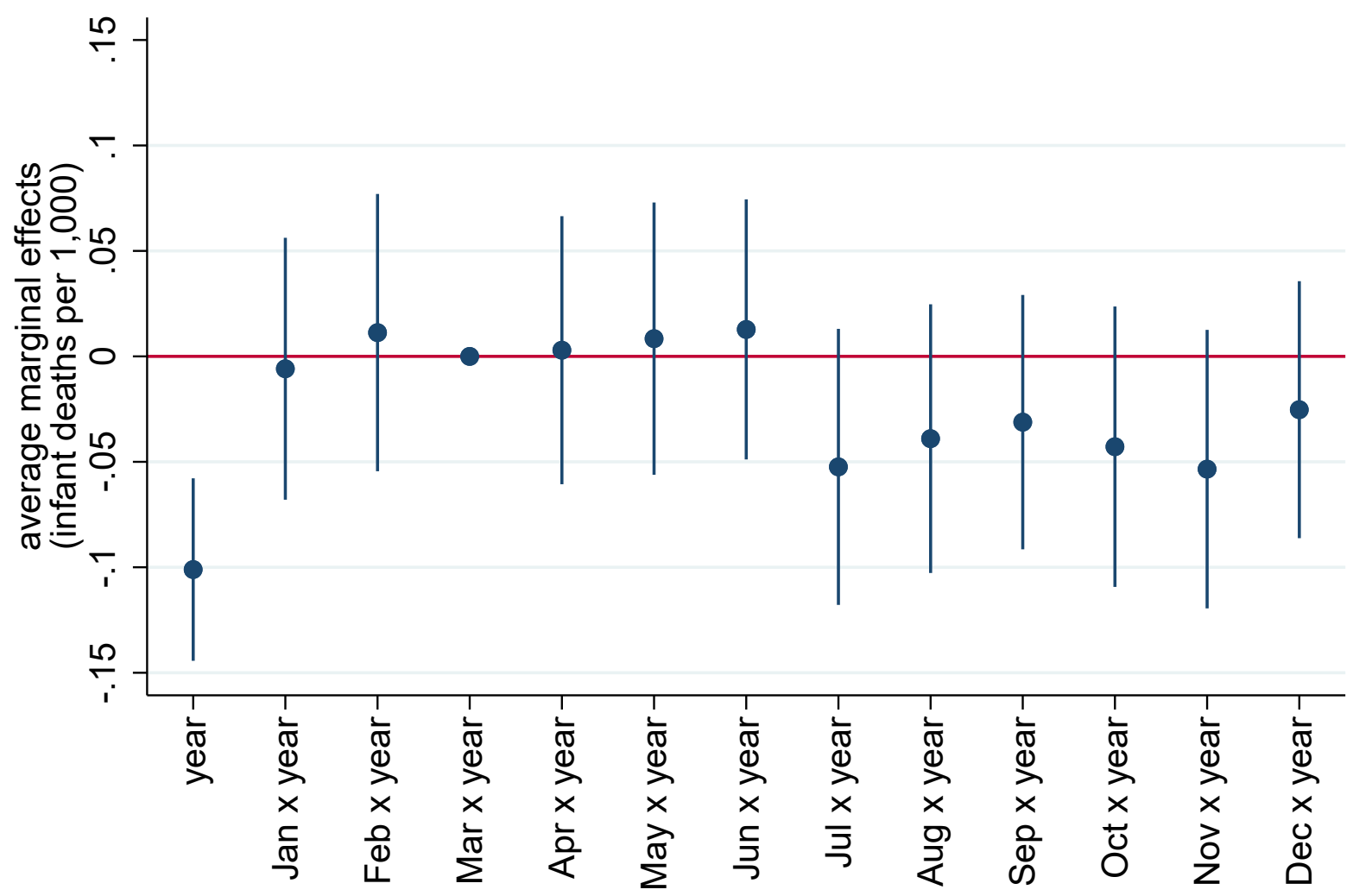

Model includes dummies for sex and age in months of the child, state, rural residence, interview month, and round. Estimates account for survey wights and clustering within the primary sampling unit. 


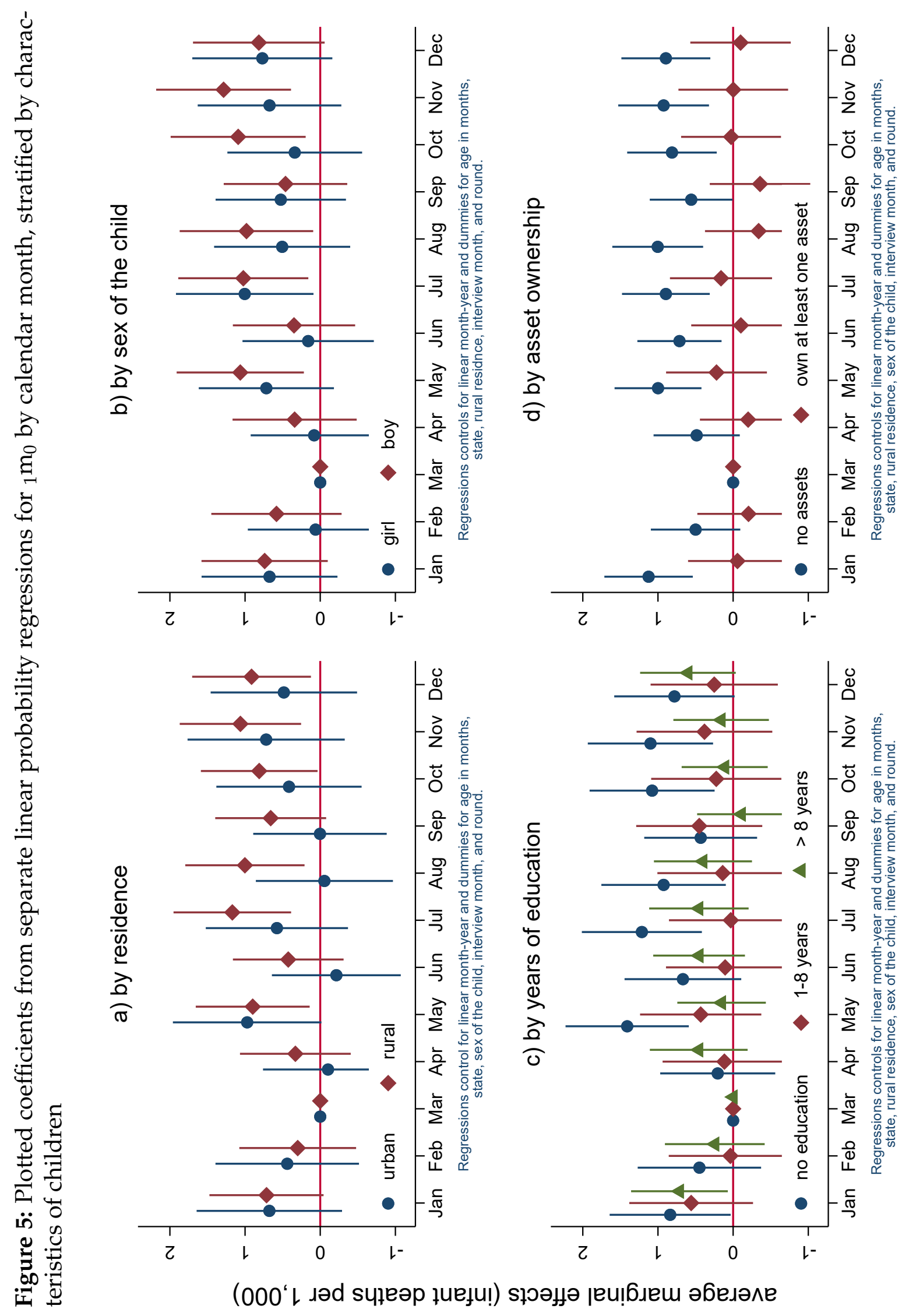


Figure 6: Plotted coefficients from separate linear probability regressions for ${ }_{1} \mathrm{~m}_{0}$ by calendar month, stratified by region

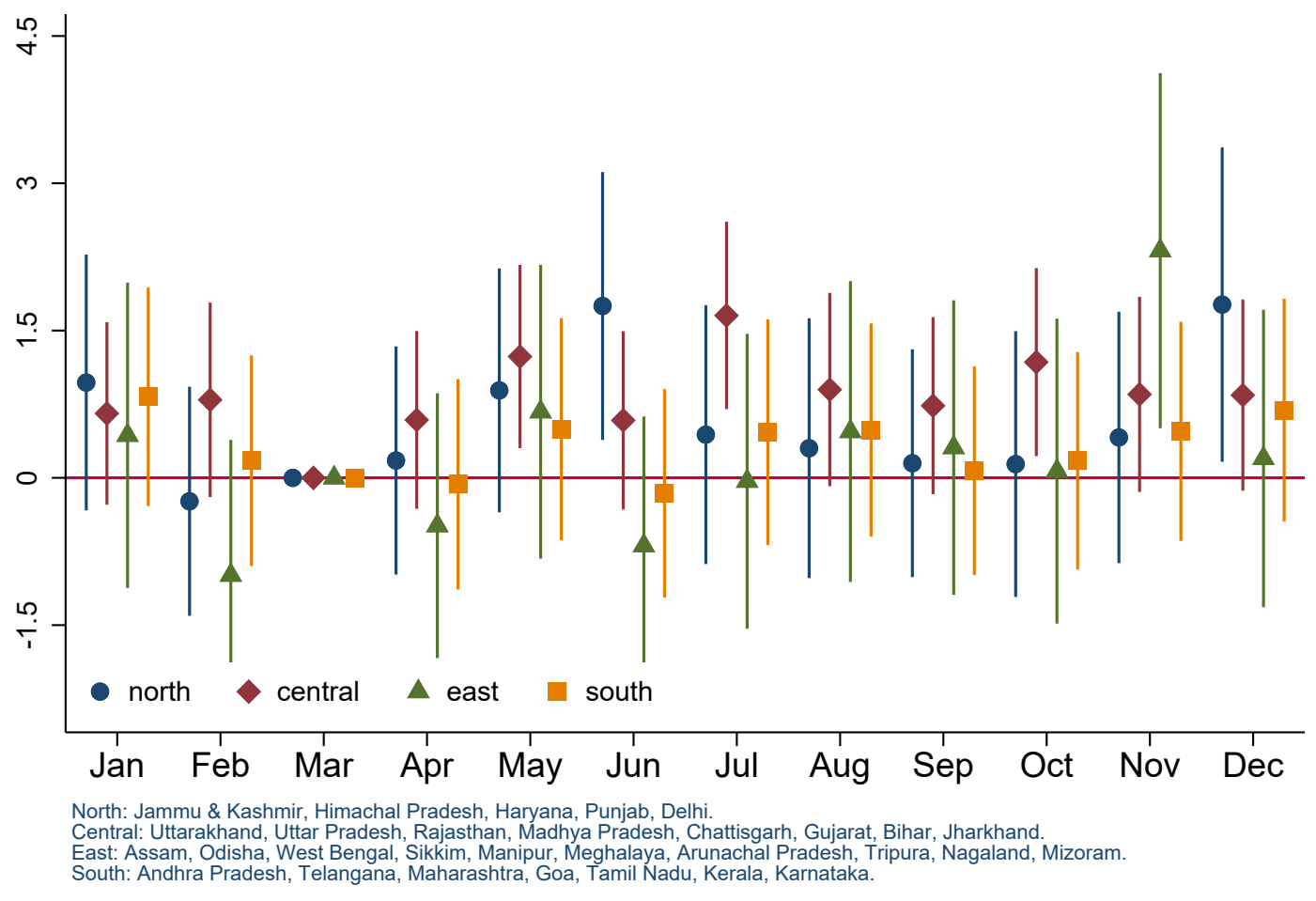


Figure 7: Seasonal variation by Koppen-Geiger climate classifications, latest NFHS round (2011-2016)
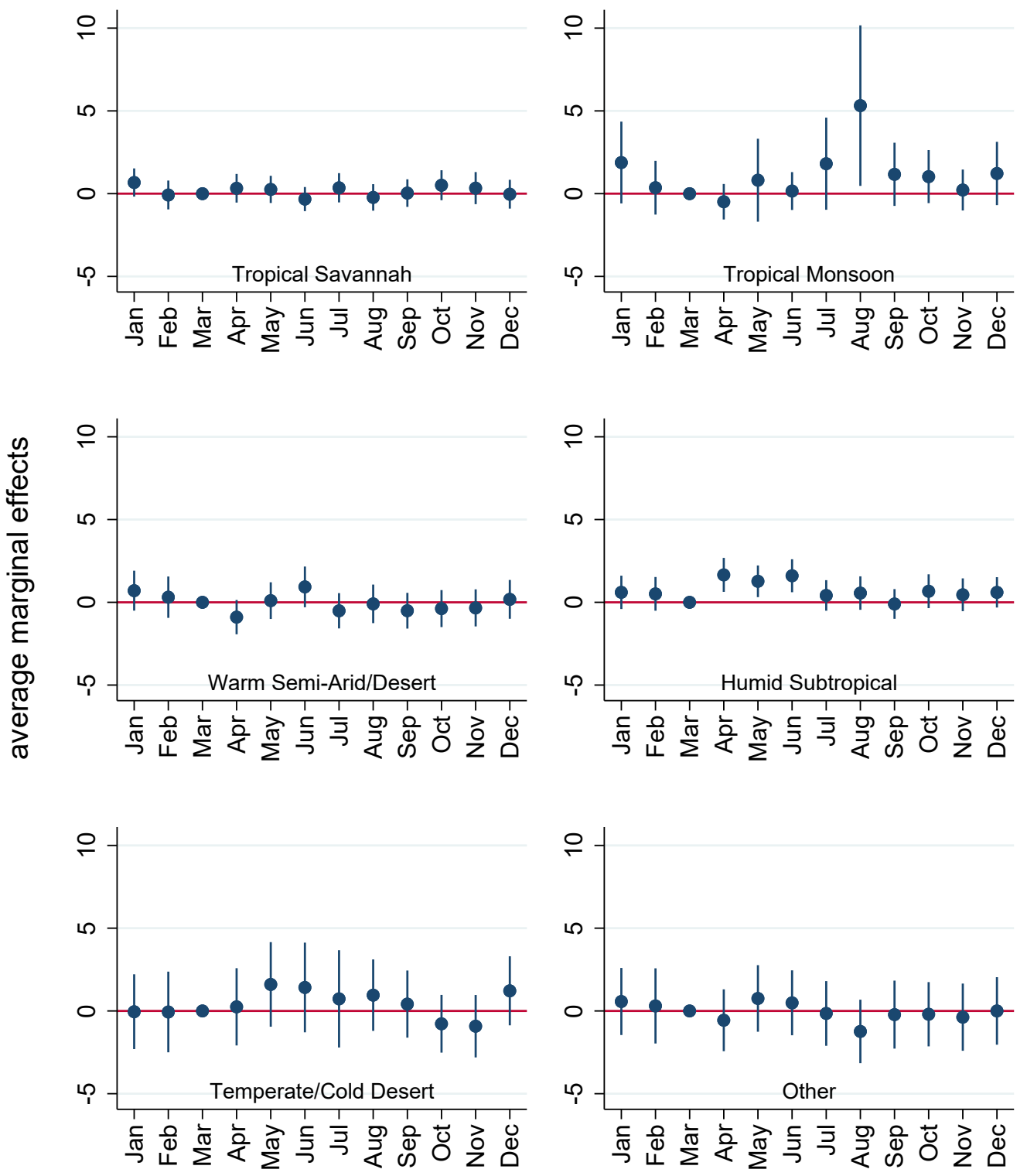

Regressions control for dummies of sex and age in months of the child, survey round, interview month, and rural residence. 


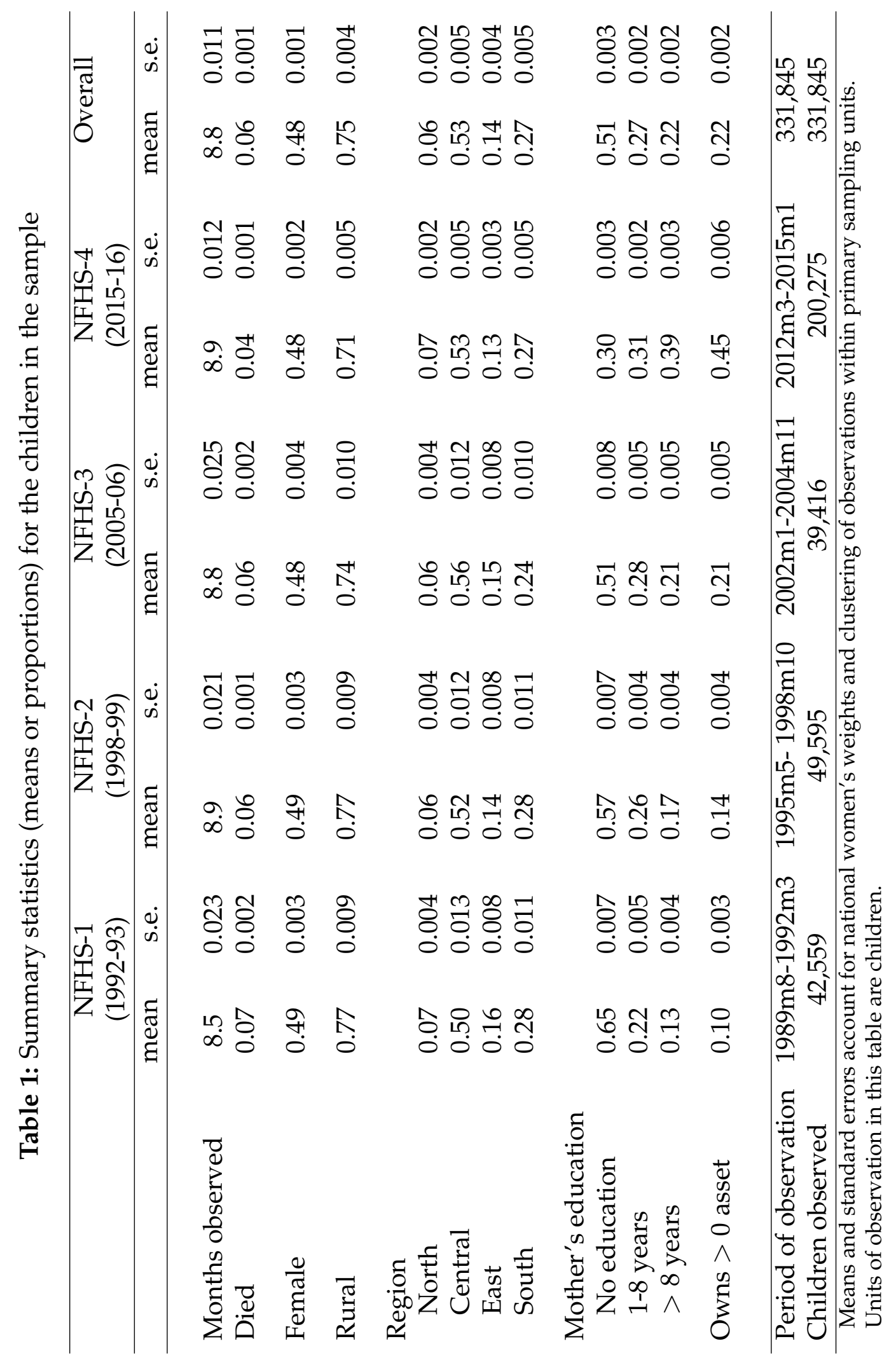


Table 2: Proportionate distribution of observed child month and deaths in the sample

\begin{tabular}{lcccc}
\hline calendar month & \multicolumn{2}{c}{ child-months } & \multicolumn{2}{c}{ deaths } \\
\hline & mean & s.e. & mean & s.e. \\
January & 0.085 & 0.0001 & 0.005 & 0.0002 \\
February & 0.077 & 0.0002 & 0.004 & 0.0002 \\
March & 0.085 & 0.0001 & 0.004 & 0.0002 \\
April & 0.076 & 0.0001 & 0.004 & 0.0002 \\
May & 0.082 & 0.0002 & 0.005 & 0.0002 \\
June & 0.082 & 0.0002 & 0.004 & 0.0002 \\
July & 0.082 & 0.0002 & 0.005 & 0.0002 \\
August & 0.090 & 0.0001 & 0.006 & 0.0002 \\
September & 0.090 & 0.0001 & 0.005 & 0.0002 \\
October & 0.090 & 0.0001 & 0.006 & 0.0002 \\
November & 0.084 & 0.0001 & 0.006 & 0.0003 \\
December & 0.077 & 0.0002 & 0.005 & 0.0003 \\
\hline $\mathrm{n}$ (observations) & $2,933,892$ & 12,479 \\
\hline
\end{tabular}

Means and standard errors account for national women's weights and clustering of observations within primary sampling units. Units of observation in this table are child-months. 
Table 3: Estimated coefficients and odds-ratios from linear probability, logistic, and complementary-log-log models of infant mortality by calendar month

\begin{tabular}{|c|c|c|c|c|c|c|}
\hline \multirow[t]{2}{*}{ model: } & \multicolumn{4}{|c|}{ linear probability } & \multirow{2}{*}{$\begin{array}{c}\text { logit } \\
(5)\end{array}$} & \multirow{2}{*}{$\begin{array}{c}\text { cloglog } \\
(6)\end{array}$} \\
\hline & (1) & (2) & (3) & (4) & & \\
\hline \multicolumn{7}{|l|}{ reference: March } \\
\hline \multirow[t]{2}{*}{ January } & $0.764^{*}$ & $0.686^{*}$ & $0.686^{*}$ & $0.705^{*}$ & $1.157^{*}$ & $1.155^{*}$ \\
\hline & $(0.319)$ & $(0.315)$ & $(0.315)$ & $(0.315)$ & $(0.081)$ & $(0.079)$ \\
\hline \multirow[t]{2}{*}{ February } & 0.176 & 0.469 & 0.460 & 0.323 & 1.075 & 1.074 \\
\hline & $(0.323)$ & $(0.321)$ & $(0.321)$ & $(0.321)$ & $(0.081)$ & $(0.080)$ \\
\hline \multirow[t]{2}{*}{ April } & -0.053 & 0.074 & 0.079 & 0.213 & 1.048 & 1.048 \\
\hline & $(0.305)$ & $(0.302)$ & $(0.302)$ & $(0.302)$ & $(0.076)$ & $(0.075)$ \\
\hline \multirow[t]{2}{*}{ May } & $0.623+$ & $0.802^{*}$ & $0.801 *$ & $0.896 * *$ & $1.229^{* *}$ & $1.226^{* *}$ \\
\hline & (0.319) & $(0.315)$ & $(0.315)$ & $(0.316)$ & $(0.087)$ & $(0.086)$ \\
\hline \multirow[t]{2}{*}{ June } & 0.144 & 0.150 & 0.148 & 0.257 & 1.051 & 1.050 \\
\hline & $(0.304)$ & $(0.301)$ & $(0.301)$ & $(0.302)$ & $(0.075)$ & $(0.074)$ \\
\hline \multirow[t]{2}{*}{ July } & $1.035^{* *}$ & $0.897^{* *}$ & $0.895^{* *}$ & $1.018^{* *}$ & $1.219 * *$ & $1.215^{* *}$ \\
\hline & $(0.326)$ & $(0.321)$ & $(0.321)$ & $(0.322)$ & $(0.085)$ & $(0.083)$ \\
\hline \multirow[t]{2}{*}{ August } & $1.595 * * *$ & $0.757^{*}$ & $0.756^{*}$ & $0.753^{*}$ & $1.137+$ & $1.135+$ \\
\hline & $(0.330)$ & $(0.325)$ & $(0.325)$ & $(0.325)$ & $(0.076)$ & $(0.075)$ \\
\hline \multirow[t]{2}{*}{ September } & $0.862^{* *}$ & 0.476 & 0.475 & 0.488 & 1.097 & 1.097 \\
\hline & $(0.309)$ & $(0.304)$ & $(0.304)$ & $(0.304)$ & $(0.073)$ & $(0.072)$ \\
\hline \multirow[t]{2}{*}{ October } & $1.566 * * *$ & $0.702^{*}$ & $0.702 *$ & $0.727^{*}$ & $1.130+$ & $1.128+$ \\
\hline & $(0.327)$ & $(0.320)$ & $(0.320)$ & $(0.322)$ & $(0.075)$ & $(0.074)$ \\
\hline \multirow[t]{2}{*}{ November } & $1.534 * * *$ & $0.948^{* *}$ & $0.951^{* *}$ & $0.987^{* *}$ & $1.189^{*}$ & $1.187^{*}$ \\
\hline & $(0.341)$ & $(0.336)$ & $(0.335)$ & $(0.336)$ & $(0.082)$ & $(0.081)$ \\
\hline \multirow[t]{2}{*}{ December } & $0.986^{* *}$ & $0.758^{*}$ & $0.764 *$ & $0.789 *$ & $1.177^{*}$ & $1.174^{*}$ \\
\hline & $(0.330)$ & $(0.326)$ & $(0.326)$ & $(0.327)$ & $(0.083)$ & $(0.081)$ \\
\hline age (in month) dummies & & $x$ & $x$ & $x$ & $x$ & $\mathrm{x}$ \\
\hline sex of the child & & $x$ & $x$ & $x$ & $x$ & $x$ \\
\hline state & & & $x$ & $x$ & $x$ & $x$ \\
\hline rural residence & & & $x$ & $x$ & $x$ & $x$ \\
\hline month of survey & & & & $x$ & $x$ & $x$ \\
\hline survey round dummies & & & & $x$ & $x$ & $x$ \\
\hline linear month year & & & & $x$ & $x$ & $x$ \\
\hline mean imr & & 4.32 & infant death & per $1,000 p$ & month & \\
\hline children & 331,845 & 331,845 & 331,845 & 331,845 & 331,845 & 331,845 \\
\hline $\mathrm{n}$ (child-months) & $2,933,892$ & $2,933,892$ & $2,933,892$ & $2,933,892$ & $2,933,892$ & $2,933,892$ \\
\hline
\end{tabular}

Source: NFHS Surveys. Estimates and clustered standard errors account for national women's weights and clustering of observations within primary sampling units. $+p<0.1{ }^{*} p<0.05,{ }^{* *} p<0.01,{ }^{* * *} p<0.001$. 
Table 4: Age-standardized ${ }_{1} \mathrm{~m}_{0}$ by calendar month and survey round

\begin{tabular}{|c|c|c|c|c|c|c|c|c|}
\hline & \multicolumn{2}{|c|}{ NFHS-1 } & \multicolumn{2}{|c|}{ NFHS-2 } & \multicolumn{2}{|c|}{ NFHS-3 } & \multicolumn{2}{|c|}{ NFHS-4 } \\
\hline & ${ }_{1} \mathrm{~m}_{0}$ & s.e. & ${ }_{1} \mathrm{~m}_{0}$ & s.e. & ${ }_{1} \mathrm{~m}_{0}$ & s.e. & ${ }_{1} \mathrm{~m}_{0}$ & s.e. \\
\hline January & 6.6 & 0.551 & 5.3 & 0.528 & 4.9 & 0.548 & 3.9 & 0.196 \\
\hline February & 6.4 & 0.603 & 4.1 & 0.455 & 5.4 & 0.576 & 3.4 & 0.232 \\
\hline March & 5.6 & 0.516 & 5.0 & 0.489 & 4.3 & 0.543 & 3.1 & 0.179 \\
\hline April & 5.9 & 0.662 & 5.2 & 0.521 & 4.3 & 0.499 & 3.4 & 0.202 \\
\hline May & 6.3 & 0.750 & 5.6 & 0.471 & 6.0 & 0.605 & 3.7 & 0.203 \\
\hline June & 6.0 & 0.652 & 5.0 & 0.411 & 4.1 & 0.528 & 3.8 & 0.205 \\
\hline July & 7.3 & 0.701 & 5.7 & 0.452 & 5.8 & 0.610 & 3.3 & 0.198 \\
\hline August & 6.6 & 0.521 & 6.1 & 0.425 & 4.7 & 0.531 & 3.4 & 0.199 \\
\hline September & 6.3 & 0.532 & 5.6 & 0.422 & 4.9 & 0.524 & 3.1 & 0.180 \\
\hline October & 7.0 & 0.550 & 5.2 & 0.384 & 5.0 & 0.503 & 3.5 & 0.199 \\
\hline November & 7.2 & 0.566 & 5.4 & 0.491 & 5.5 & 0.555 & 3.3 & 0.203 \\
\hline December & 6.8 & 0.559 & 5.1 & 0.492 & 5.8 & 0.756 & 3.4 & 0.191 \\
\hline s.d. $\left({ }_{1} \mathrm{~m}_{0}\right)$ & & 535 & & 84 & & 636 & & 237 \\
\hline c.v. $\left({ }_{1} \mathrm{~m}_{0}\right)$ & & 082 & & 92 & & 127 & & 069 \\
\hline s.d. $\left(\log _{1} m_{0}\right)$ & & 083 & & & & 126 & & 069 \\
\hline A. Observed ${ }_{1} \mathrm{~m}_{0}$, annualized & & 8.0 & & & & 50.3 & & 1.2 \\
\hline B. March ${ }_{1} \mathrm{~m}_{0}$, annualized & & 6.6 & & .7 & & 51.8 & & 37.6 \\
\hline C. Difference (A - B) & & 1.4 & & & & 8.5 & & 3.7 \\
\hline
\end{tabular}

Means and standard errors account for national women's weights and clustering of observations within primary sampling units. Units of observation in this table are child-months. s.d: standard deviation. c.v.: coefficient of variation. 


\section{SUPPLEMENTARY APPENDIX FOR ONLINE PUBLICATION}

\section{Additional methodological notes}

The approach used in this paper and outlined in the lexis diagram is compatible with several assumptions. The full list of compatible assumptions includes:

- All births are in the middle of the month (on the 15th); and all deaths are on the exact day the child attains the age (in months) at which they died

- All births are in the middle of the month (on the 15th); and all deaths are within the fifteen days of reaching a particular age (in months)

- All births are in the middle of the month (on the 15th); and all deaths are on the last day of the month, i.e. at age in months the child died +0.49 of a month

- All births are distributed uniformly within the month; and all deaths are on the exact day the child attains the age (in months) at which they died

The approach is also robust to alternative assumptions. For instance, we can assume that within a calendar-month, births are randomly distributed across days. Then, for neonatal deaths, we know the exact month a child died because age at death in days is available. For deaths at ages greater than age zero month, we can assume that the death was fifteen days after the day a child turned a particular age-month. So a child who died at age two months can be assumed to have died 74 days after the day s/he was born. Appendix figure A8 shows the unadjusted and adjusted mortality rates below age 1 for this approach (red squares). Comparing with the mortality rates using the main approach outlined in the paper (blue circles) reveals minor differences. It is worth noting that the risk mortality declines rapidly within the first year of life in India (Hill, 1995; Guillot et al., 2012). Hence, deaths are more likely to be close to the day a child turns a particular month than towards the middle or the end of that age-month. Hence, the blue circles are more closer to reality than the red squares in terms of deaths, even if the red squares are a closer approximation to reality than the blue circles in terms of births. 
Figure A1: Seasonality in births

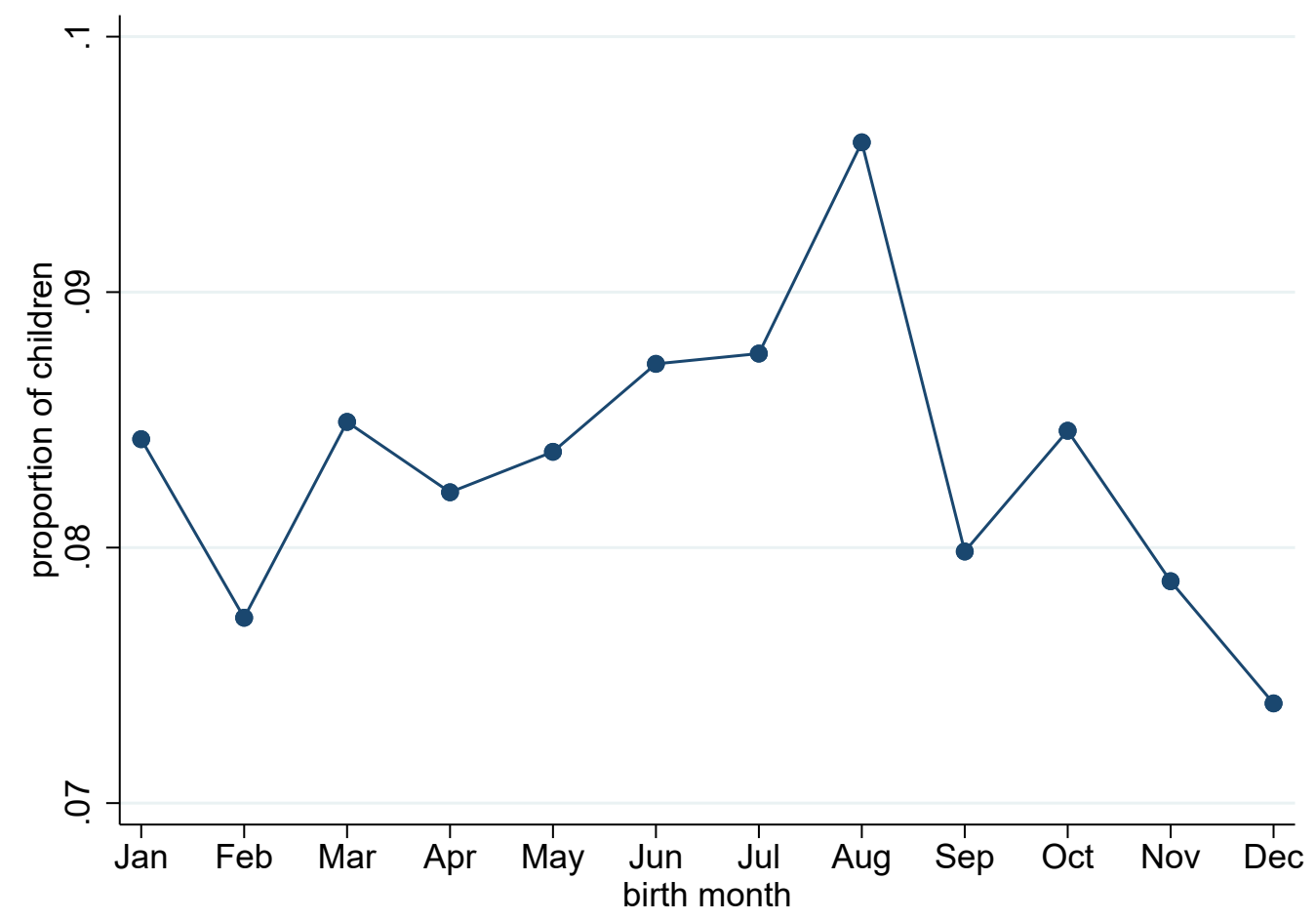


Figure A2: Plotted coefficients from separate linear probability regressions, showing ${ }_{1} \mathrm{~m}_{0}$ by calendar month and residence, for earlier and latest NFHS rounds

NFHS 1, 2, \& 3

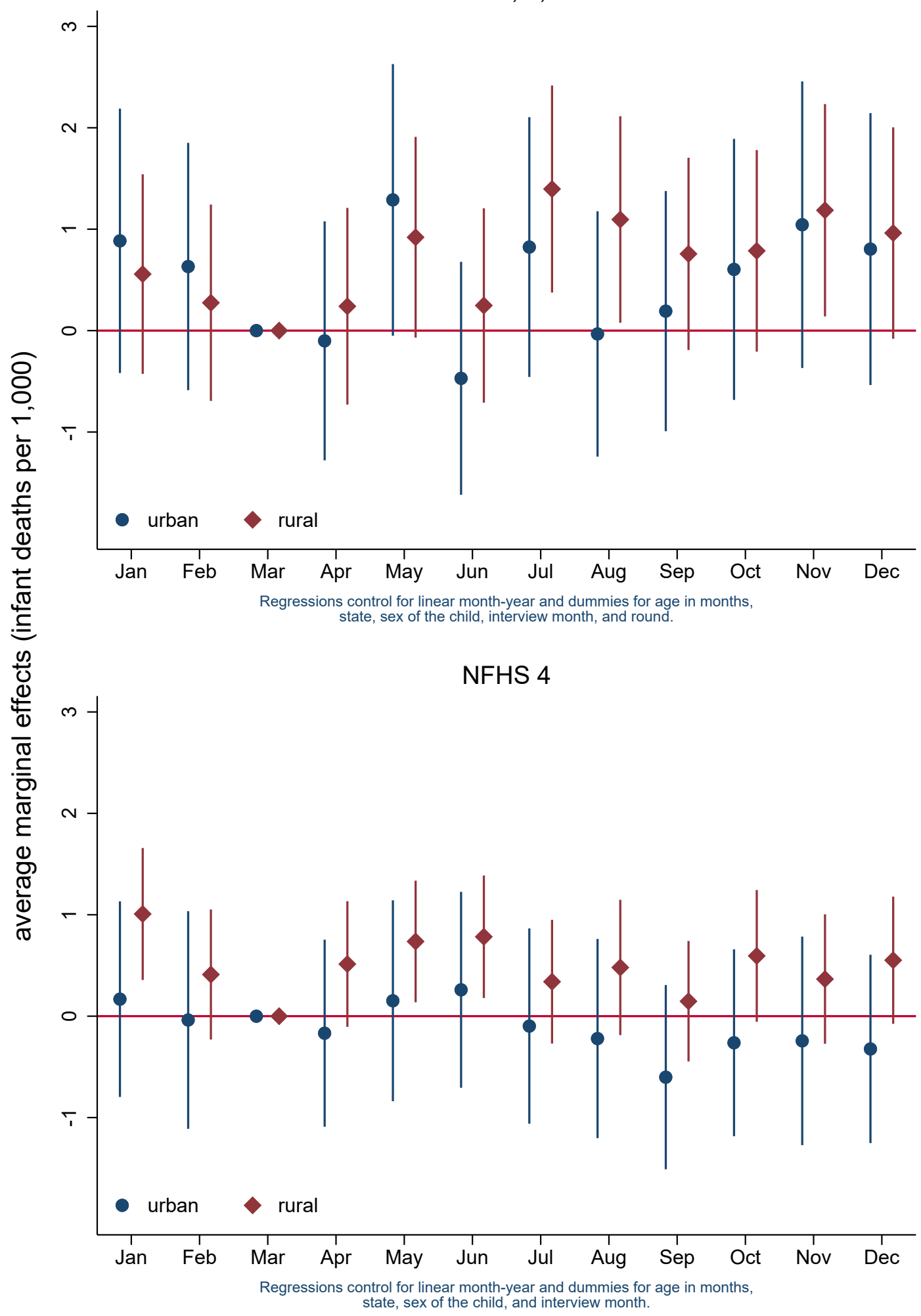

All estimates account for survey wights and clustering within the primary sampling unit. 
Figure A3: Seasonal variation by asset ownership,for earlier and latest NFHS rounds

Round 1, 2, and 3

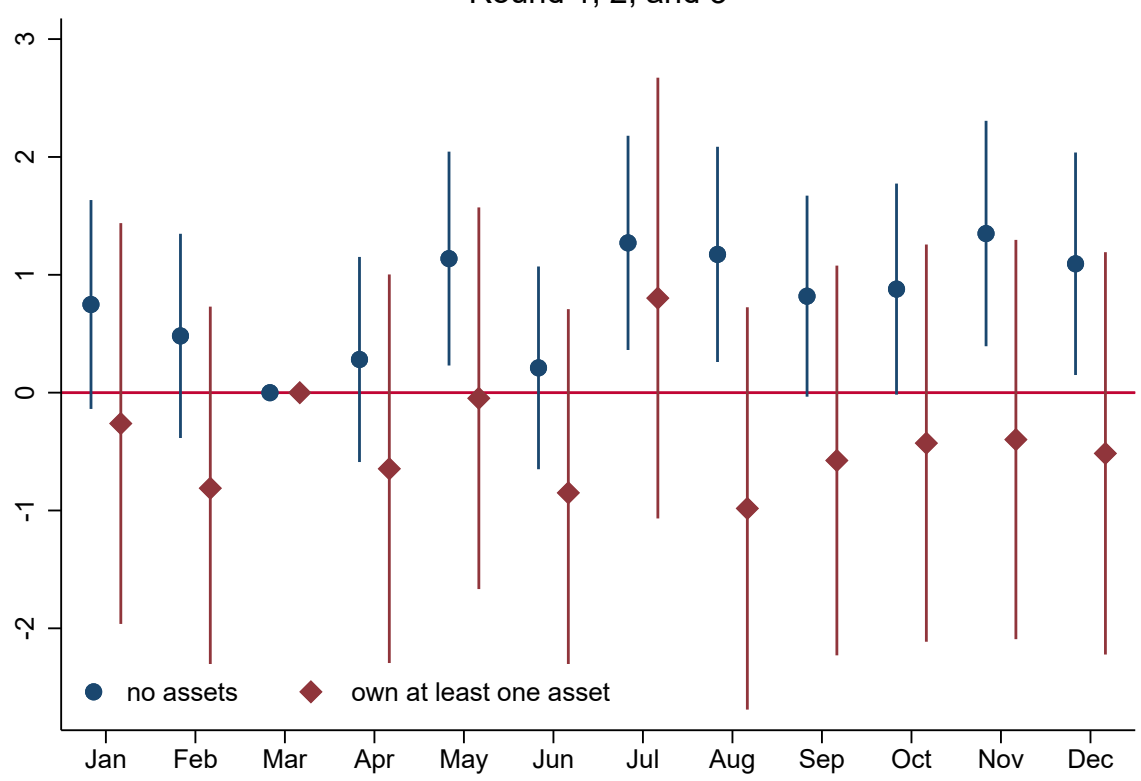

Round 4

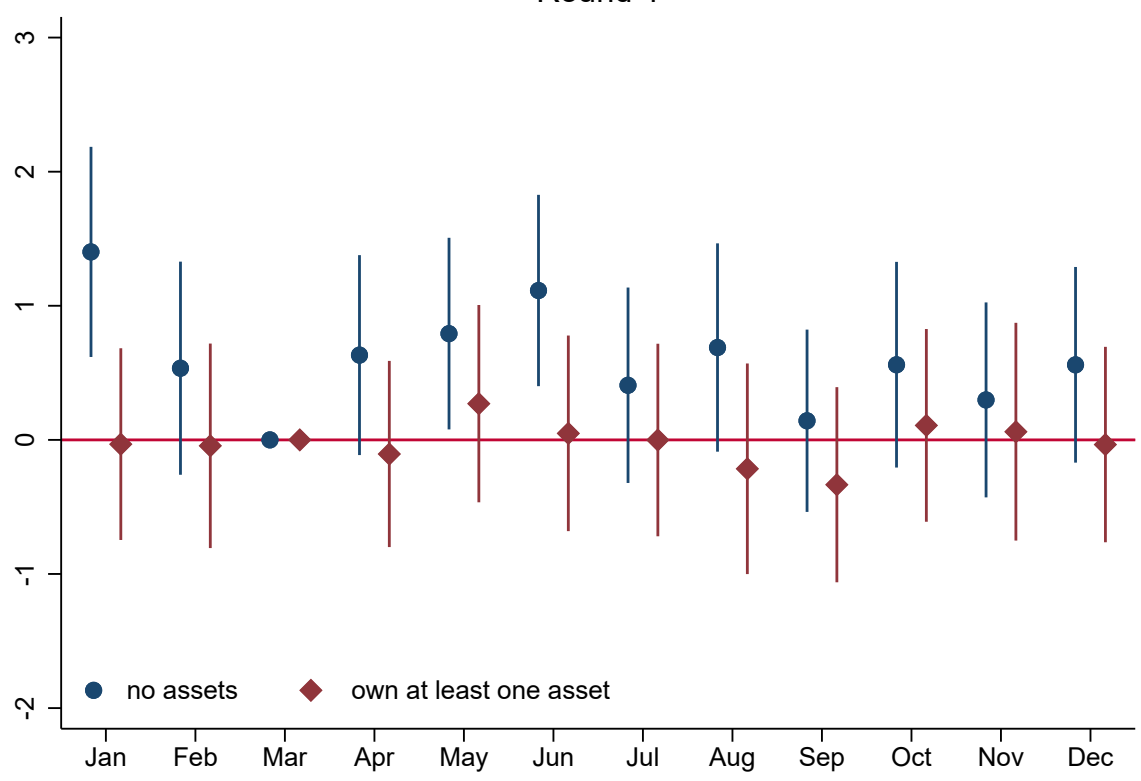

Regressions controls for linear month-year and dummies for age in months, state, rural residence, sex of the child, interview month, and round. 
Figure A4: Results from alternative regression specifications to control for time and age
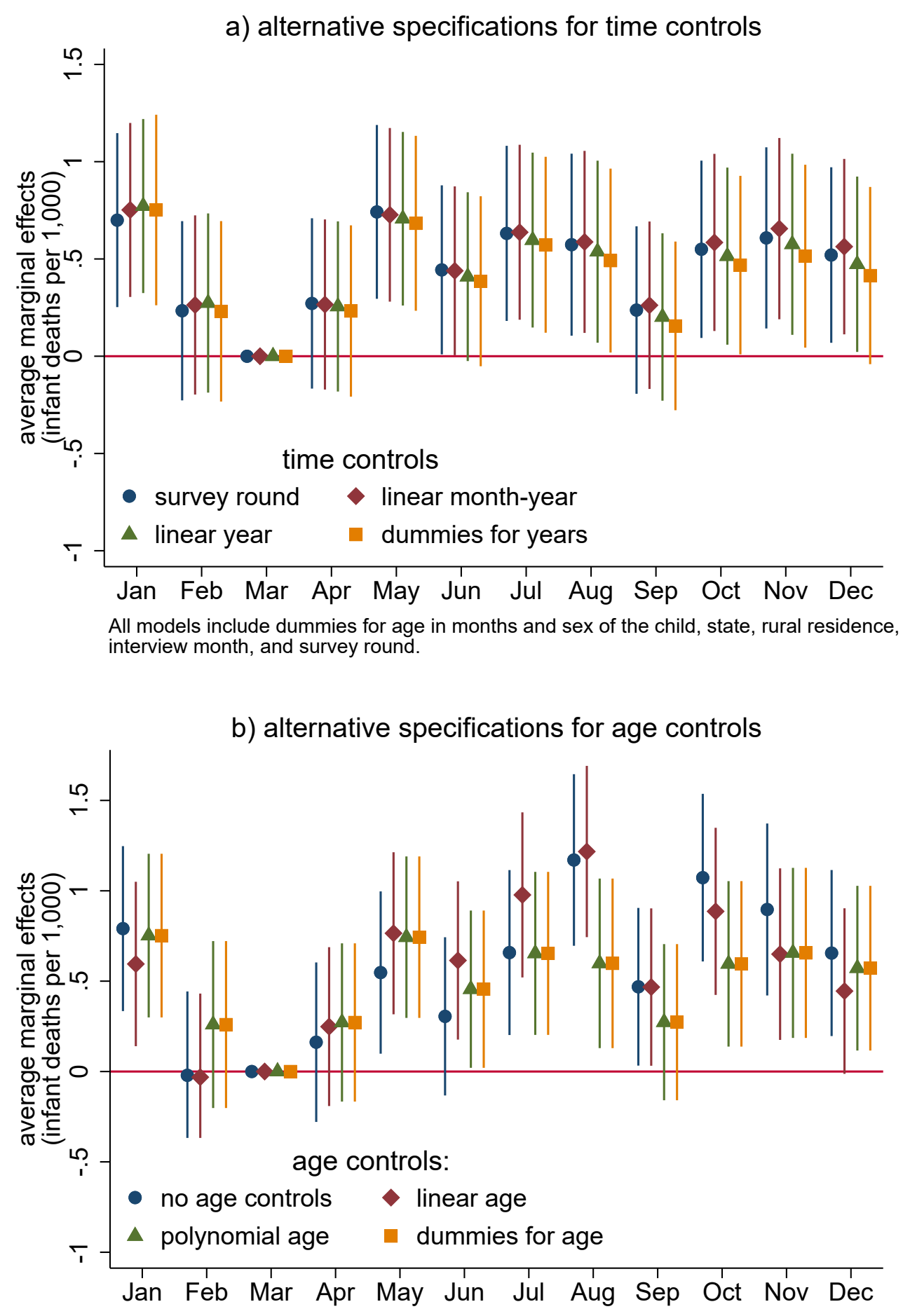

All models include linear month-year and dummies for sex of the child, state, rural residence, interview month, and survey round. 
Figure A5: Seasonal variation in neonatal and post-neonatal mortality

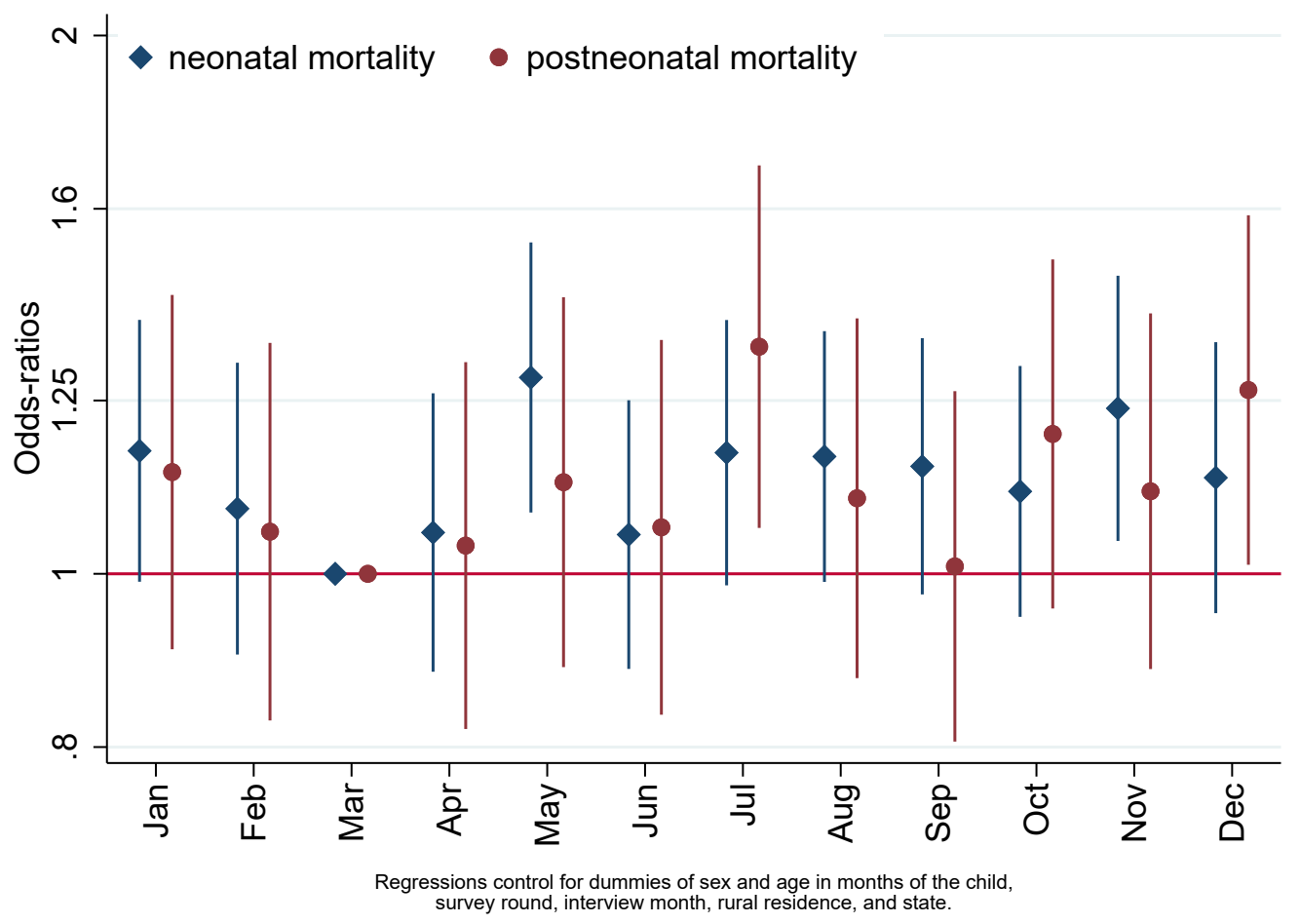


Figure A6: Seasonal variation by access to household environmental technologies

a) Seasonal variation by household sanitation use

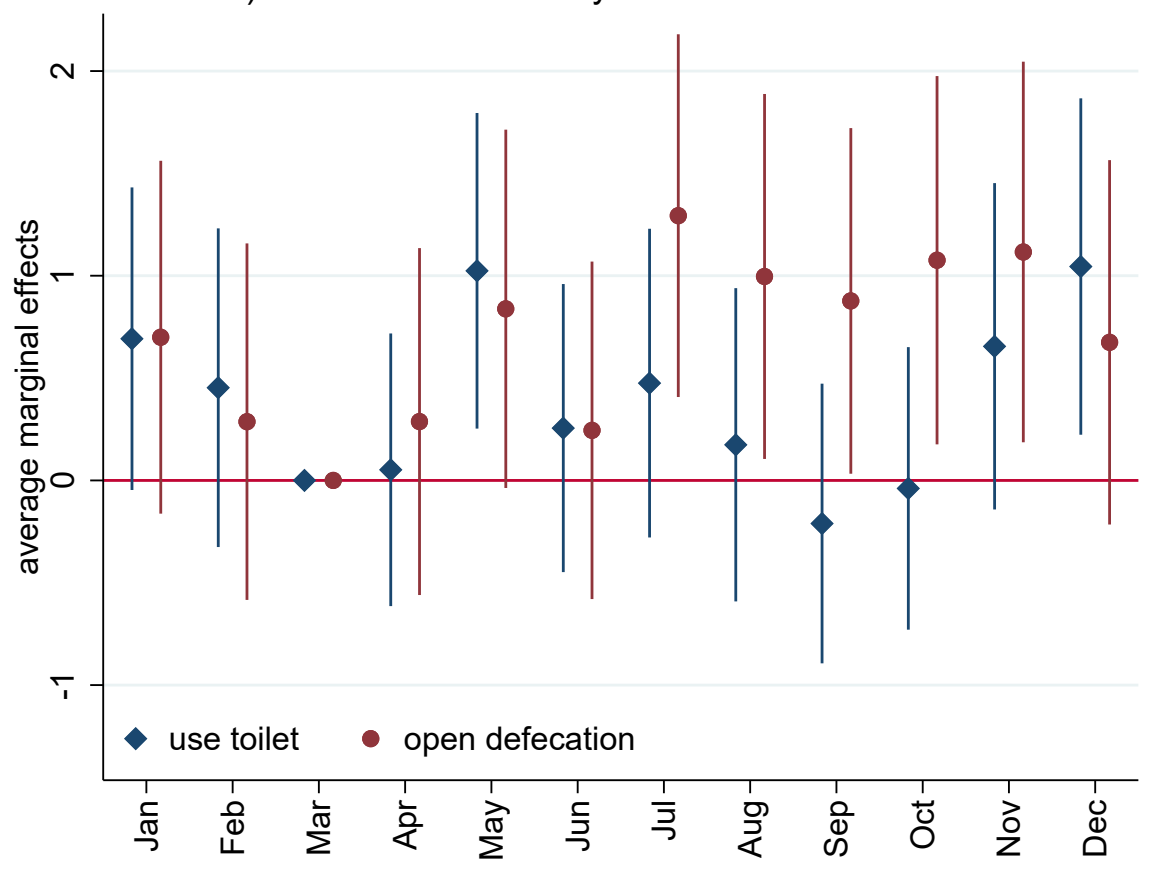

b) Seasonal variation by household fuel use

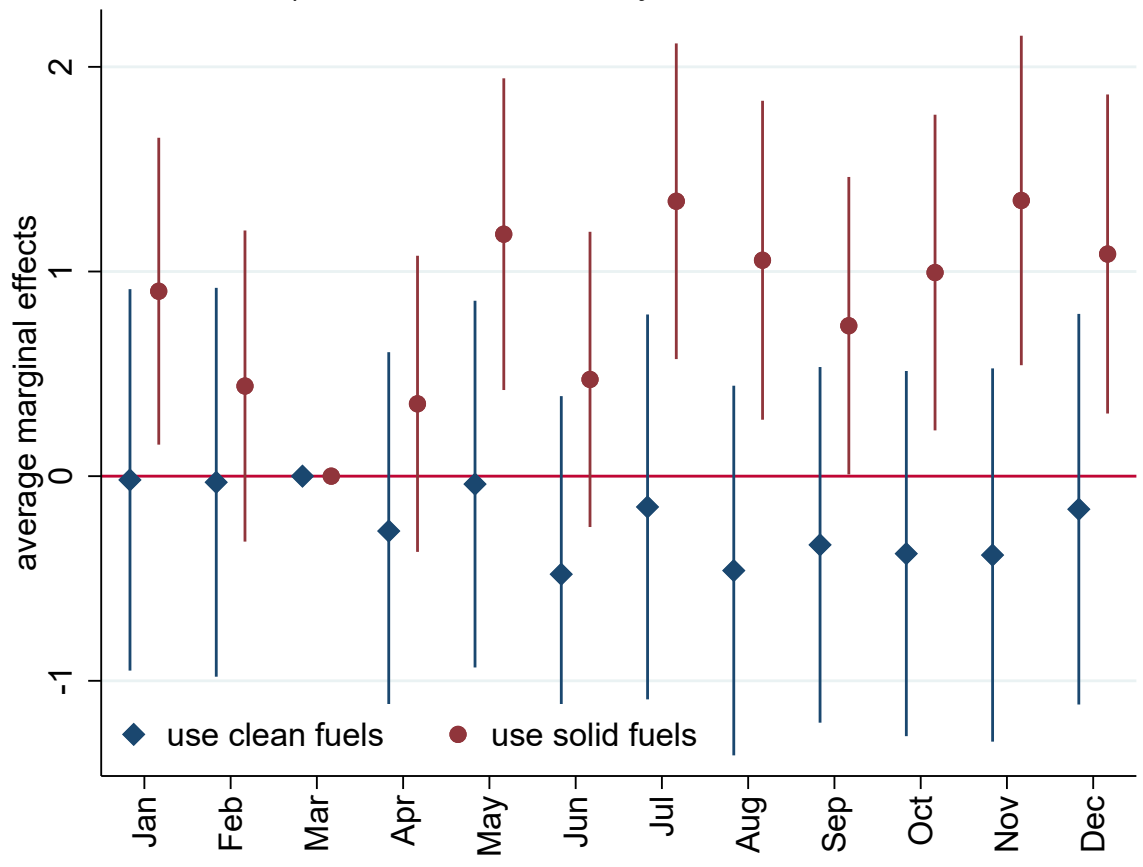

Regressions control for dummies of sex and age in months of the child, survey round, interview month, rural residence, and asset counts. 
Figure A7: Heaping in reporting age at death and mortality estimates with and without mortality at age 6 months

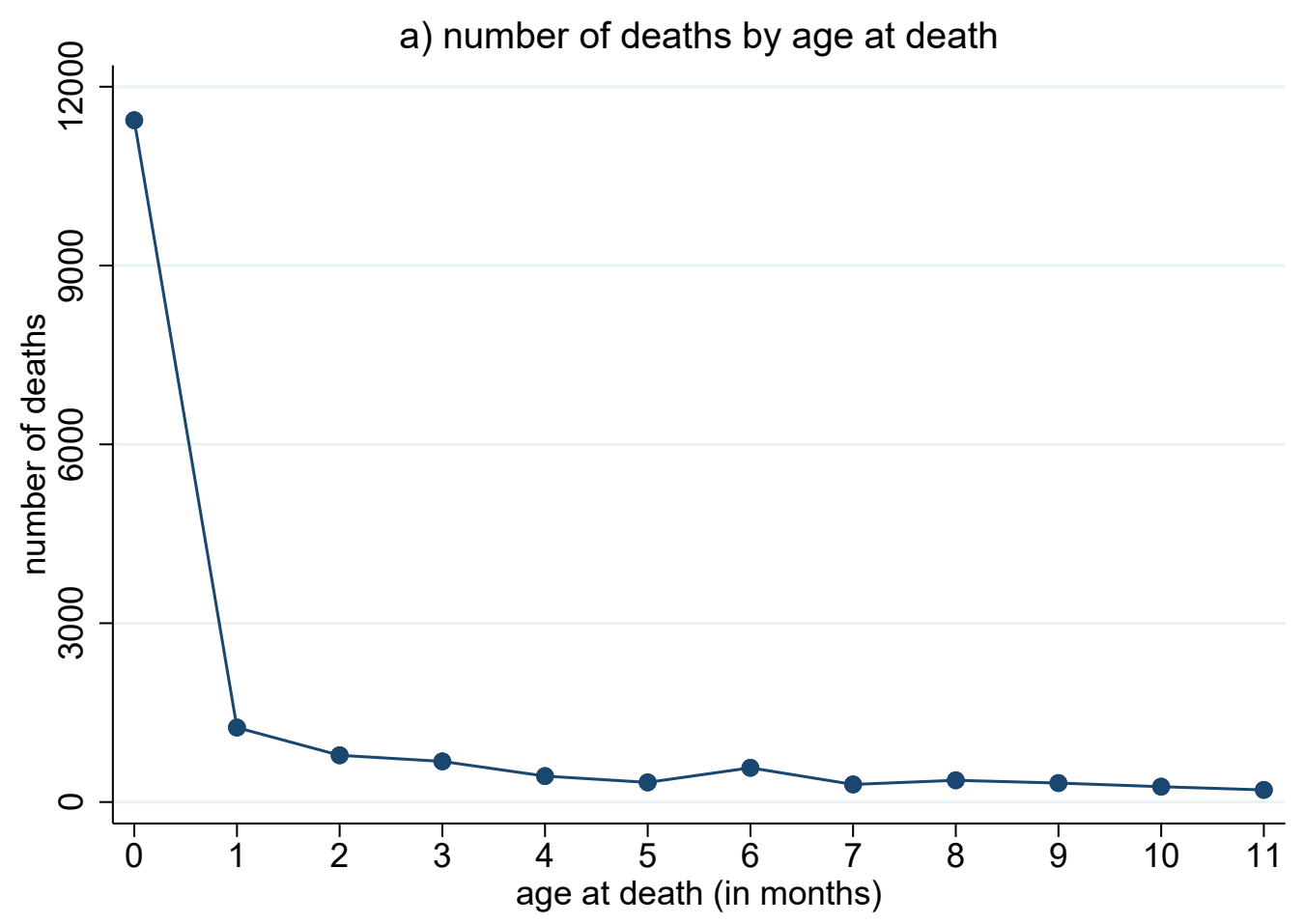

b) infant mortality estimates

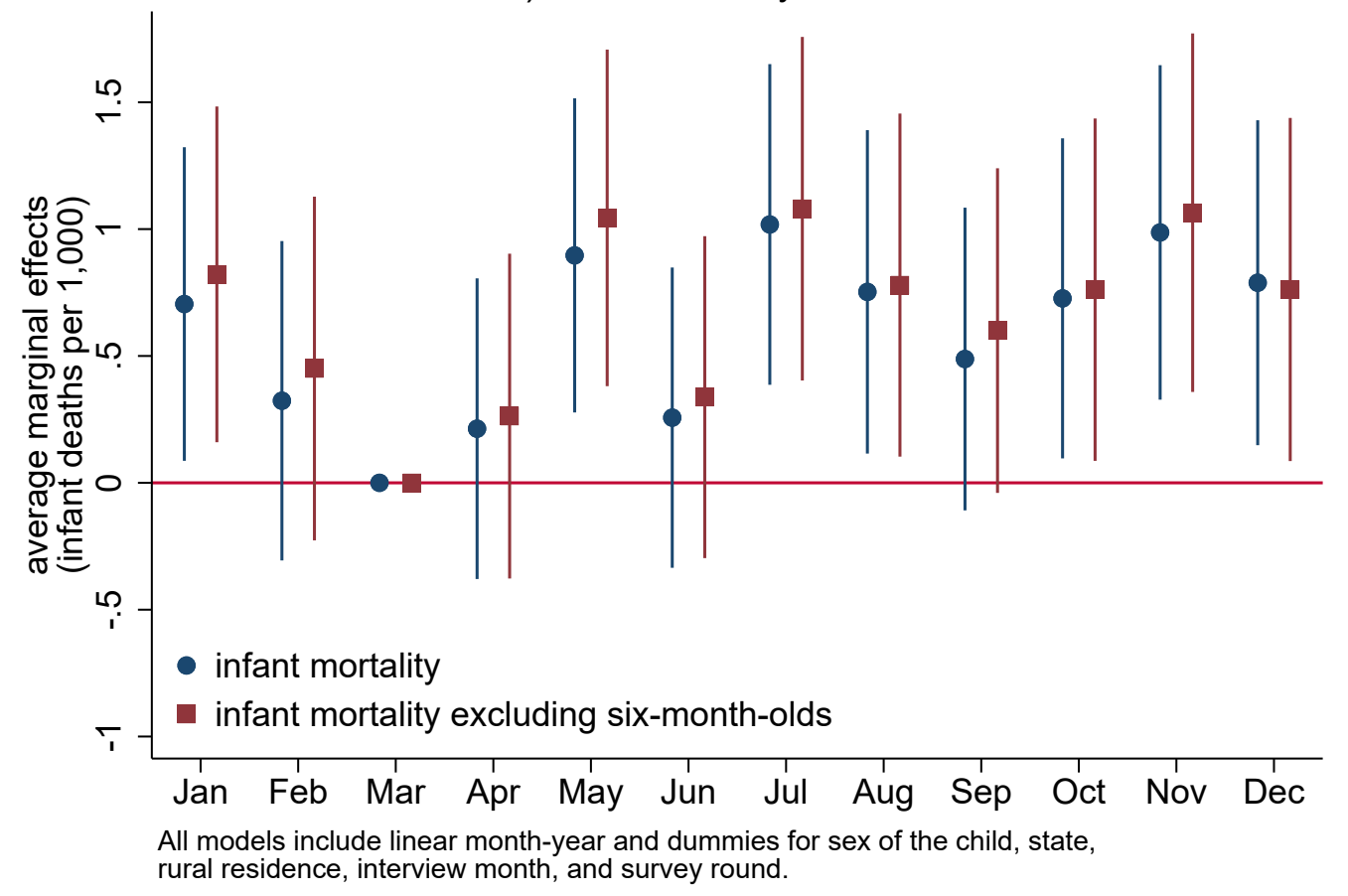


Figure A8: Unadjusted and age-standardized ${ }_{1} \mathrm{~m}_{0}$ based on alternative estimation approaches

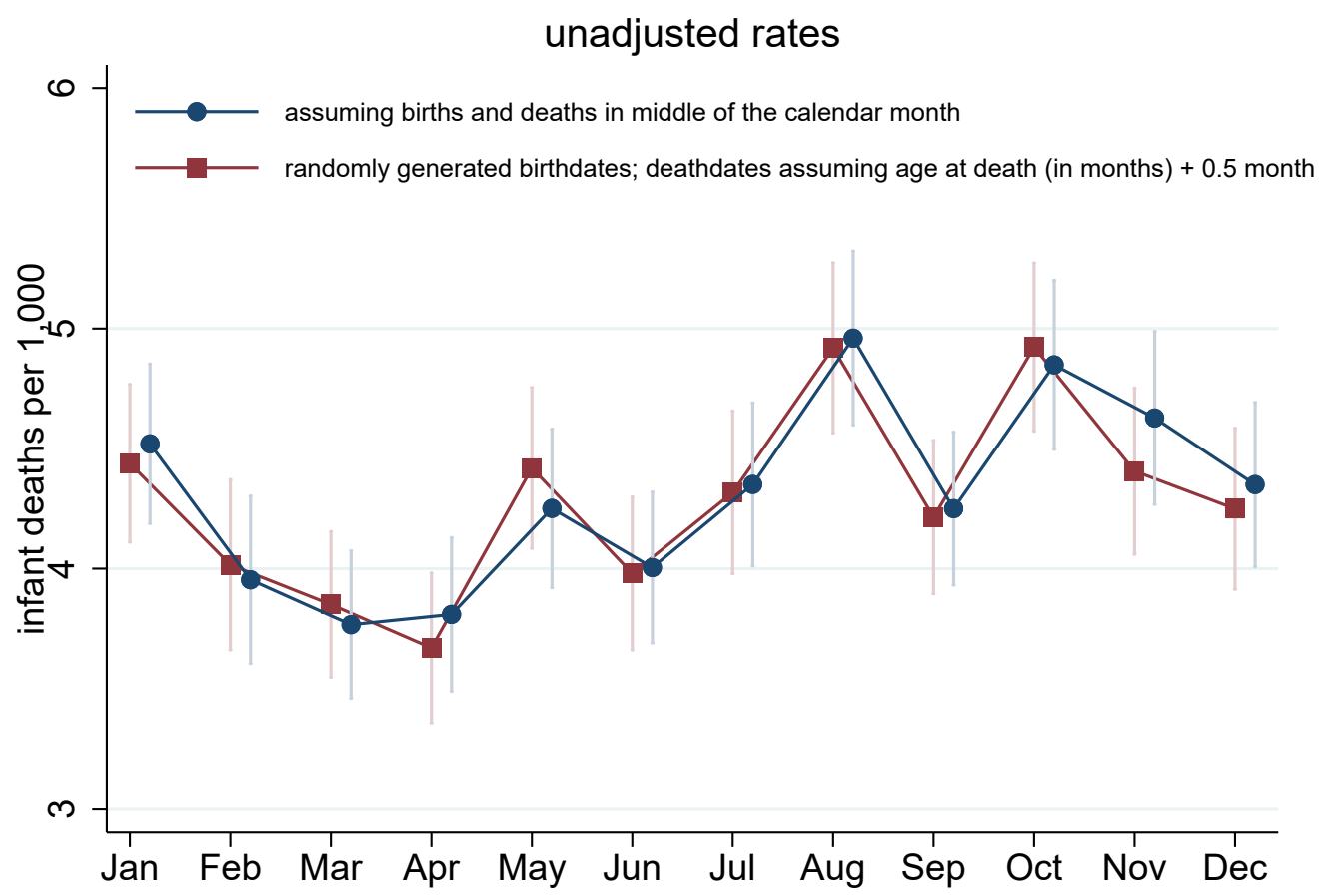

Note: Mean and $95 \% \mathrm{Cl}$ estimates account for survey weights and clustering of observations within the primary sampling unit.

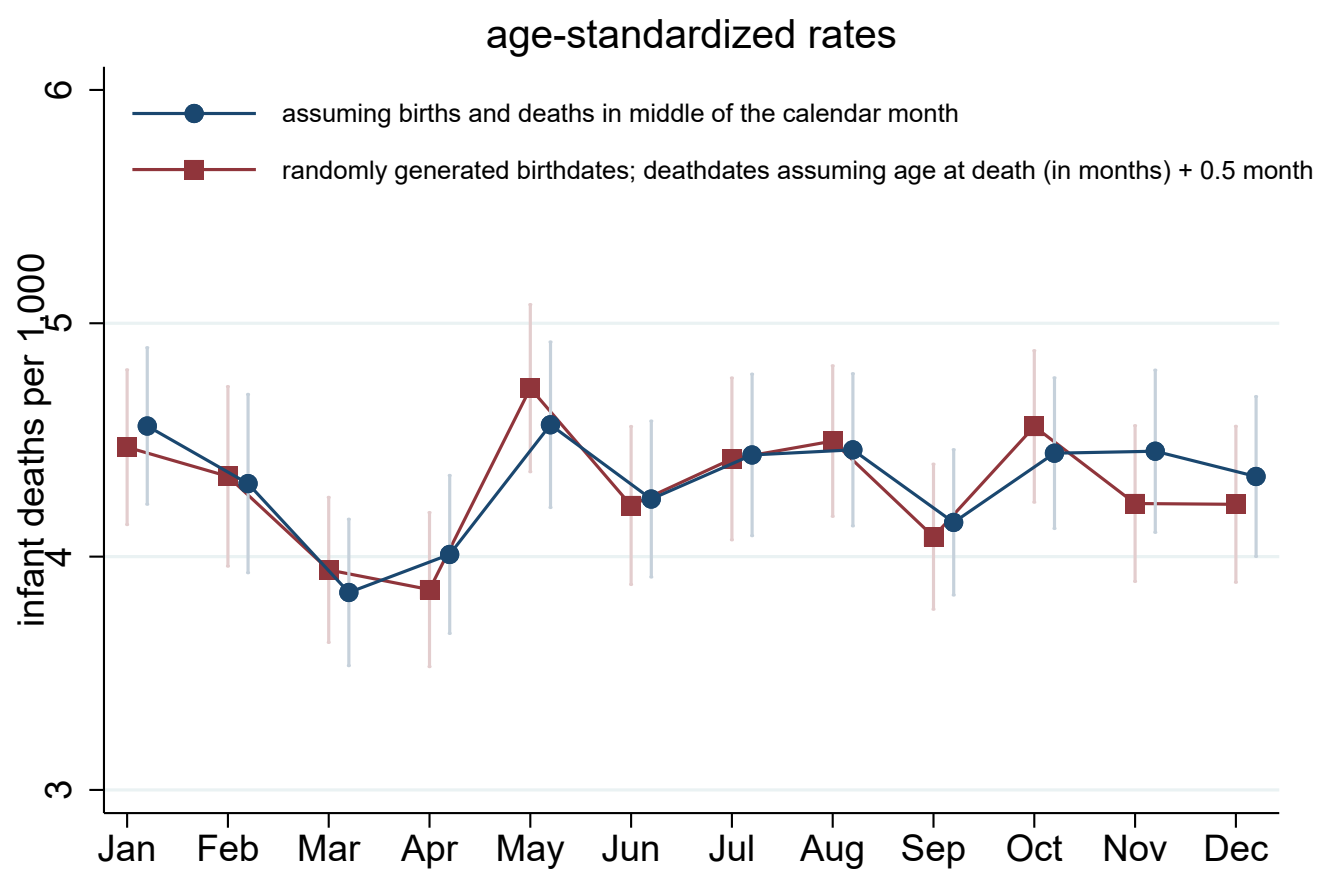

Note: Mean and $95 \% \mathrm{Cl}$ estimates account for survey weights and clustering of observations within the primary sampling unit. Estimates are age-standardized to match the distribution of age (in monhts) for each calendar month with the overall age distrbution.

Note: Observations are from pooled sample, for child-months from all four NFHS rounds. 